Research Article

\title{
Characterization of Prototype Formulated Particleboards from Agroindustrial Lignocellulose Biomass Bonded with Chemically Modified Cassava Peel Starch
}

\author{
Stephen Warui Kariuki (D), Jackson Wachira (D), Millien Kawira, \\ and Genson Murithi Leonard \\ Department of Physical Sciences, University of Embu, P.O. Box 6-60100, Embu, Kenya \\ Correspondence should be addressed to Stephen Warui Kariuki; stephowarui@yahoo.com
}

Received 7 October 2019; Accepted 24 October 2019; Published 11 November 2019

Academic Editor: Marinos Pitsikalis

Copyright ( 2019 Stephen Warui Kariuki et al. This is an open access article distributed under the Creative Commons Attribution License, which permits unrestricted use, distribution, and reproduction in any medium, provided the original work is properly cited.

Conventional methods of making particleboards utilize wood chips. This has resulted in a decrease in the tree cover due to the increase in wood demand. The effect has been climatic change. Wood is bound using phenol formaldehyde resin. Because of the decrease in the forest cover, alternative lignocellulose materials are required. In this study, lignocellulose materials used include sugarcane bagasse, maize stock, and rice husks. The cassava-starch mix with borax was used as a binder in particleboard formulation. The lignin content was determined, and its effect on properties of boards was investigated. The resultant composite material was molded at a pressure of $6.5 \mathrm{~N} / \mathrm{mm}^{2}$ and at $30^{\circ} \mathrm{C}$. The resultant particleboards had mean densities ranging from 0.604 to $0.611 \mathrm{~g} / \mathrm{cm}^{3}$. The modulus of elasticity ranged from $2364.2 \mathrm{~N} / \mathrm{mm}^{2}$ to $3329.93 \mathrm{~N} / \mathrm{mm}^{2}$, modulus of rupture ranged from $13.55 \mathrm{~N} / \mathrm{mm}^{2}$ to $14.83 \mathrm{~N} /$ $\mathrm{mm}^{2}$, and internal bonding ranged from $1.613 \mathrm{~N} / \mathrm{mm}^{2}$ to $2.370 \mathrm{~N} / \mathrm{mm}^{2}$. The performance of the board was dependent on the lignocellulose material used. Fourier transform infrared spectroscopy analysis showed that main chemical bonding in the particleboard resulted from esterification of $-\mathrm{COOH}$ from lignocellulose and $\mathrm{OH}$ - from starch. The particleboards formulated were found to be of low-density-fibre standard used in a similar manner to the conventional low-density particleboards.

\section{Introduction}

Crop residue is an alternative raw material for use in the construction industry [1]. Particleboards are used in the construction industry. Conventional methods of construction involve the use of wood from trees as the main raw material. Because of the decrease in the tree cover, researchers have focused on the use of crop residues as a substitute for wood; however, some crop residues have not been used. Crop residues contain high lignin content [2] and have remain underutilized [3]. Crop residues are disposed off through burning in open fields [4]. In addition, crop residues contain hemicellulose and cellulose which contain hydroxyl and carboxylate groups. The functional groups provide reactive sites for polycondensation polymerization [2]. These inherent reactive sites are underutilized as wood particles are encapsulated with the binder during particleboard formulation. Commonly used binders are phenol and urea formaldehydes [5].
Surface properties of the lignocellulose material are of importance in the compatibility of composite materials. Interfacial interactions between components of the composite material are controlled to an extent by chemical composition and morphology. Surface modification is covalently bonded through esterification. Esterification is enhanced through activation of the agents used in modification before treatment of the lignocellulose material. Inactive modifying agents result in insufficient interfacial adhesion that leads to moisture intrusion. Incompatibility results in decreased mechanical properties of particleboards due to poor stress transition from one material to the other. Interfacial adhesion and chemical approaches are enhanced by addition of coupling agents such as alkali treatment, esterification, and use of coupling materials. Coupling agents specifically create significant bonds between the lignocellulose material and other polymer matrices. Coupling agents include a nucleophile-containing molecule. 
Lignocellulose materials such as crop residues are composed of lignin, cellulose, and hemicellulose. These components contain hydroxyl functional groups. Hydroxyl groups determine the physical and chemical dimensions of a material and are chemically modified to carboxylate and aldehyde groups. Aldehydes such as formaldehyde are currently used as a component of resins used as a binder. The carboxylate group is the major functional group utilized during the esterification process. The carboxylate group is formed by oxidation of the hydroxyl group using oxidizing agents [6]. Oxidizing agents include hydrogen peroxide. Hydrogen peroxide decomposes in alkaline media to produce hydroperoxy anion $\left(\mathrm{HOO}^{-}\right)$[7] as follows:

$$
\mathrm{H}_{2} \mathrm{O}_{2} \rightleftharpoons \mathrm{HOO}^{-}+\mathrm{H}^{+}
$$

Hydroperoxy anion reacts with undissociated $\mathrm{H}_{2} \mathrm{O}_{2}$ to form highly reactive hydroxyl radicals $(\mathrm{OH})$ and superoxide $\left(\mathrm{O}_{2}{ }^{-}\right)$as illustrated in the following reaction:

$$
\mathrm{H}_{2} \mathrm{O}_{2}+\mathrm{HOO}^{-} \longrightarrow \mathrm{H}^{+}+\mathrm{O}_{2}^{-}+\mathrm{H}_{2} \mathrm{O}
$$

Hydrogen peroxide under alkaline media therefore produces peroxide anion that cleaves the side chains of lignin and opens the benzene ring to form oxalic acid, formic acid, and malonic acid [7], as shown in Scheme 1.

Hydroxyl groups in cellulose are converted to carboxylic acid and aldehydes [8], as shown in Scheme 2.

Cleavage of the lignocellulose material with an oxidizing agent leads to synthesis of a mixture of functional groups such as carboxylate and aldehyde. Hydroxyl groups combine through etherification. A hydroxyl group reacts with the carboxylic group through condensation polymerization to form a covalent bond through esterification. Research has shown that chemical treatment of cellulose fibres and lignin enhances the binding efficiency of natural fibres and lignin compounds into the starch composite matrix [9]. Lignin functional groups are activated by bases [10]. Activated lignin leads to increased reactive sites with other polymers [11]. This results in production of natural fibre-reinforced polymer matrix composites [12]. Lignin has other inherent characteristics in that it plasticizes starch [13].

Bio-based adhesives are an alternative to formaldehydebased adhesives to use as binders in particleboard formulation [14-16]. Various starch modifications on their crystalline nature include chemical treatments such as oxidation [17] and air [18], esterification [19], and cationization [20, 21]. Physical modifications of starch include mechanical activation [22], microwave $[23,24]$, ultrasonic degradation $[25,26]$, heatmoisture treatment [27], and enzymatic treatment [28-30]. Modified starch has been utilized in particleboard formulation [31-34]. Bio-based binders such as cassava peel starch are an alternative source of functional groups. Chemical compatibility results in formation of a strong chemical bond [35].

Starch abundance has diverted its use from food to nonfood applications [36]. Some of the nonfood applications include synthesis of bioplastic materials [37]. Alkali treatment of starch molecules involves breaking of intramolecular and intermolecular hydrogen bonding that holds the structure together. Starch molecules are hydrolyzed with an alkali to form a nucleophile [38], as shown in Scheme 3.
Copolymerization of natural polymers from crops emerges as a solution to the high cost of biodegradable materials [39]. The biocomposite material from cassava starch, fibres, and silica had poor internal bonding due to the use of a weak base in pretreatment of cellulose fibres [40]. Crop residues are alternative raw materials for copolymerization with other natural polymers such as starch that allow the country production to grow [41]. Particleboards made from commercially formulated particles and starch-based adhesives did not meet Japanese industrial standards for particleboards (JIS A5908) [42]. This was a result of the use of water to hydrolyze starch. Particleboards made from cassava root and cassava starch mix failed to fulfill recommended ANSI/A2 08.1-1999 standards [43]. Starch was hydrolyzed with water at $80^{\circ} \mathrm{C}$, which is a higher gelatinization temperature of starch [44].

Biopolymers derived from renewable resources are an emerging class of advanced materials with a wide range of industrial applications [45]. Researchers have focused on renewable polymer blends such as composite materials [46]. Major natural polymers include starch, lignin, cellulose, and hemicellulose. Chemical modification of these polymers yields materials with tailored properties suitable for use in formulation of composite materials molded to form particleboards. Various particleboards are used in the building industry (Scheme 4).

The starch-lignin matrix showed reduction in enthalpy of combustion [49]. Therefore, the main objective of this work was to evaluate the physical and mechanical properties of particleboards formulated between chemically treated lignin and modified starch blend. Polyblending is one of the most commercially important and inexpensive ways of developing new materials from readily available base polymers [50]. Polyblending aims at production of highperformance materials at a reduced cost. Crop residues involved were rice husks, maize stalk, and sugarcane bagasse. Cassava starch was used as a binder.

\section{Materials and Methods}

2.1. Preparation of Materials. Maize stalks were collected at random from a farm in Nakuru County $\left(0^{\circ} 18^{\prime} \mathrm{S}, 36^{\circ} 4^{\prime} \mathrm{E}\right)$, sugarcane bagasse from Kisumu County $\left(0^{\circ} 5^{\prime} \mathrm{S}, 34^{\circ} 46^{\prime} \mathrm{E}\right)$, and rice husks from Mwea $\left(0^{\circ} 37^{\prime} \mathrm{S}, 37^{\circ} 20^{\prime} \mathrm{E}\right)$, Kirinyaga County, which are all counties in Kenya. Maize stalk was cut into small sizes less than $20 \mathrm{~mm}$ in width using a chuff cutter and ground using a mill crusher to particle size less than $10 \mathrm{~mm}$. Sugarcane bagasse which was obtained from the sugar factory was not ground further. Rice husks were ground using the mill to particle size less than $10 \mathrm{~mm}$. All the three plant residues were dried in an oven at $105^{\circ} \mathrm{C}$, to a constant mass. Cassava was obtained at random from Thika, Kiambu County. It was peeled, chopped into smaller pieces, and sun-dried to a constant mass. The dried cassava was ground using a maize mill to 100 mesh size. The ground cassava starch was then placed in an oven at $105^{\circ} \mathrm{C}$ to a constant mass. Dried cassava was pulverized to 150 mesh size. 


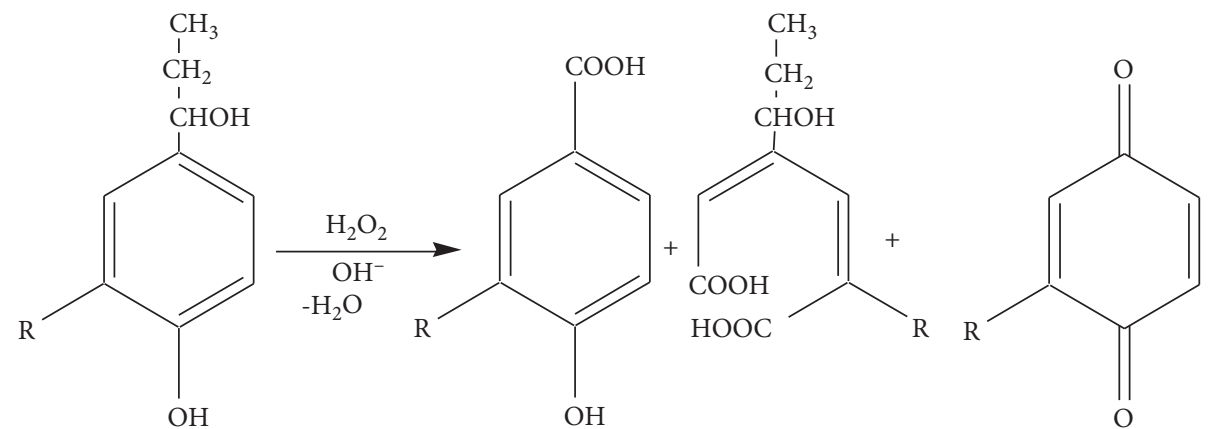

Scheme 1: Cleavage and oxidation of the lignin material in the lignocellulose material using perhydroxyl anion.

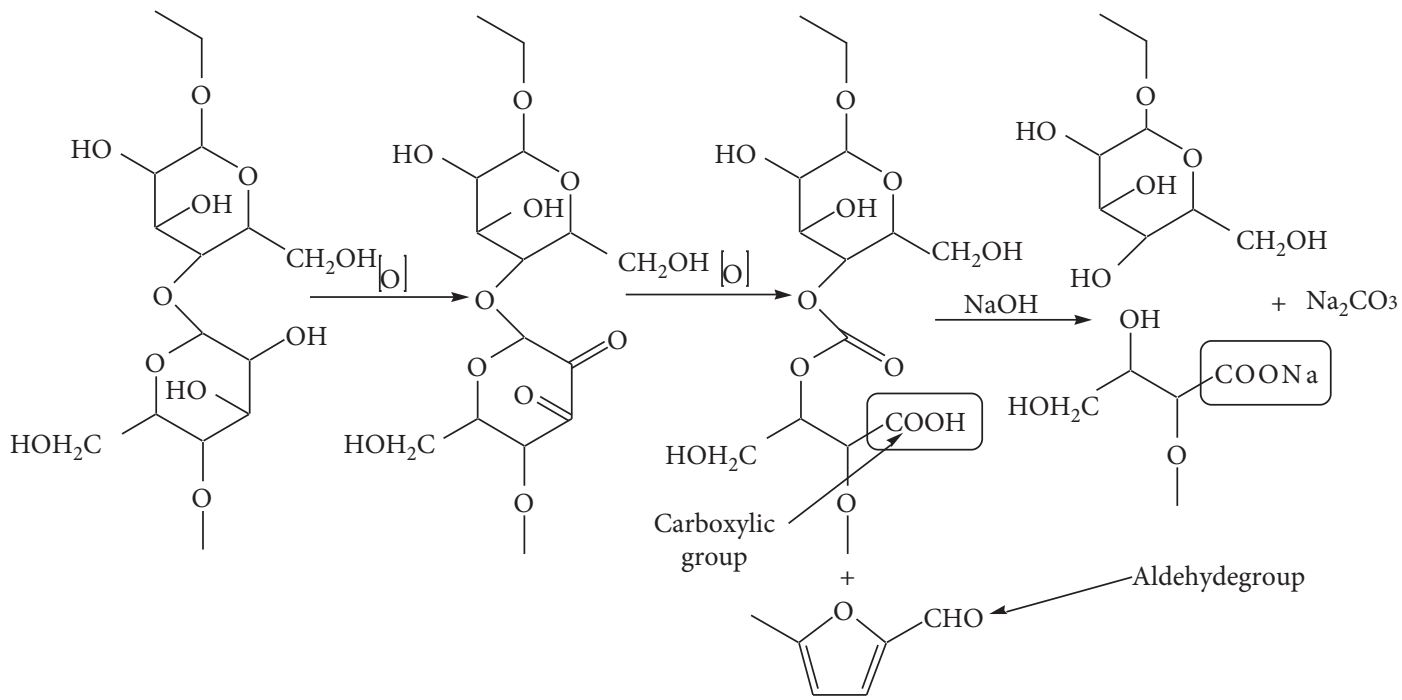

Scheme 2: Oxidation of cellulose using hydrogen peroxide in alkaline media.

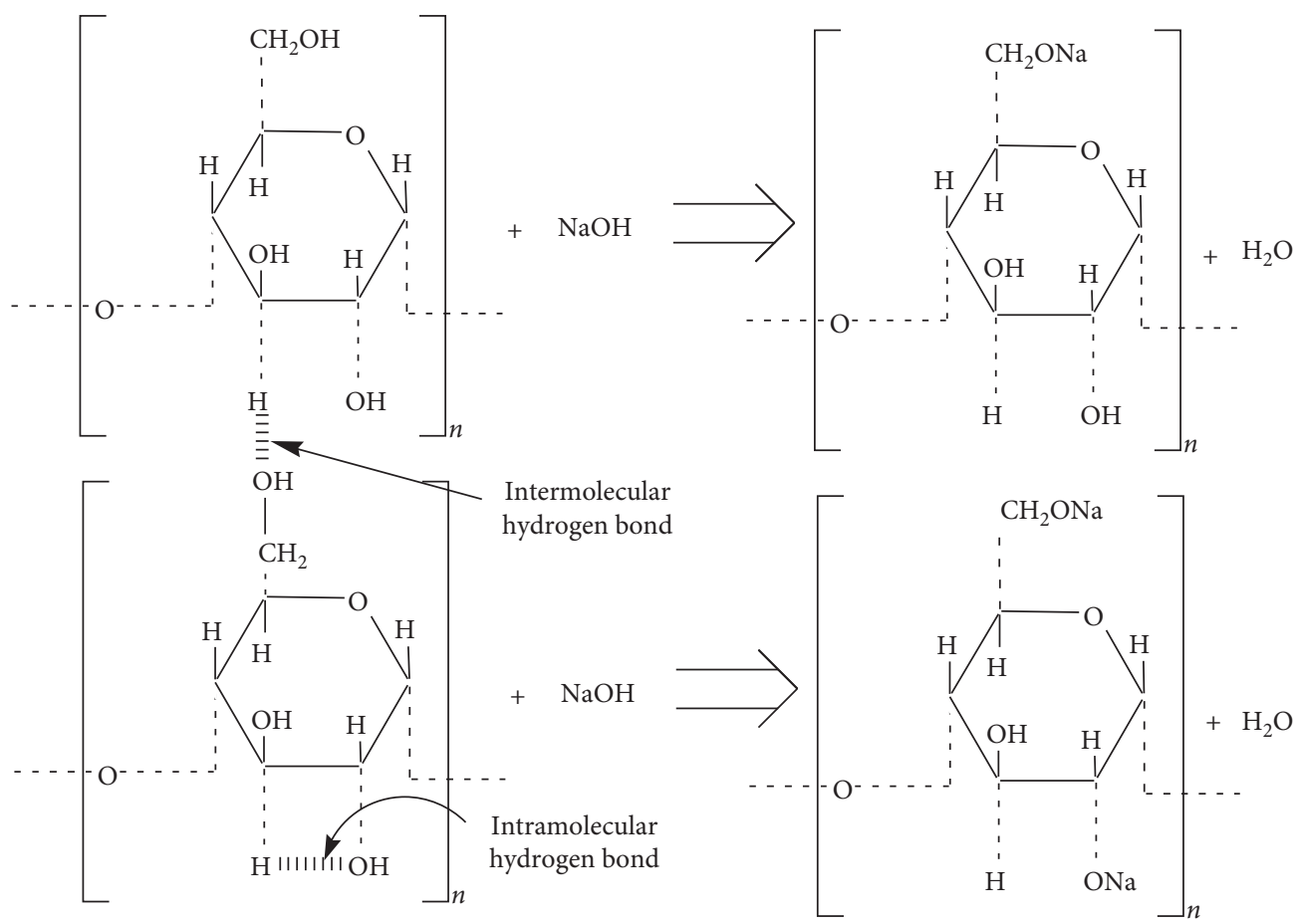

Scheme 3: Effects of sodium hydroxide on changing the starch morphology by breaking intra- and intermolecular hydrogen bonding. 


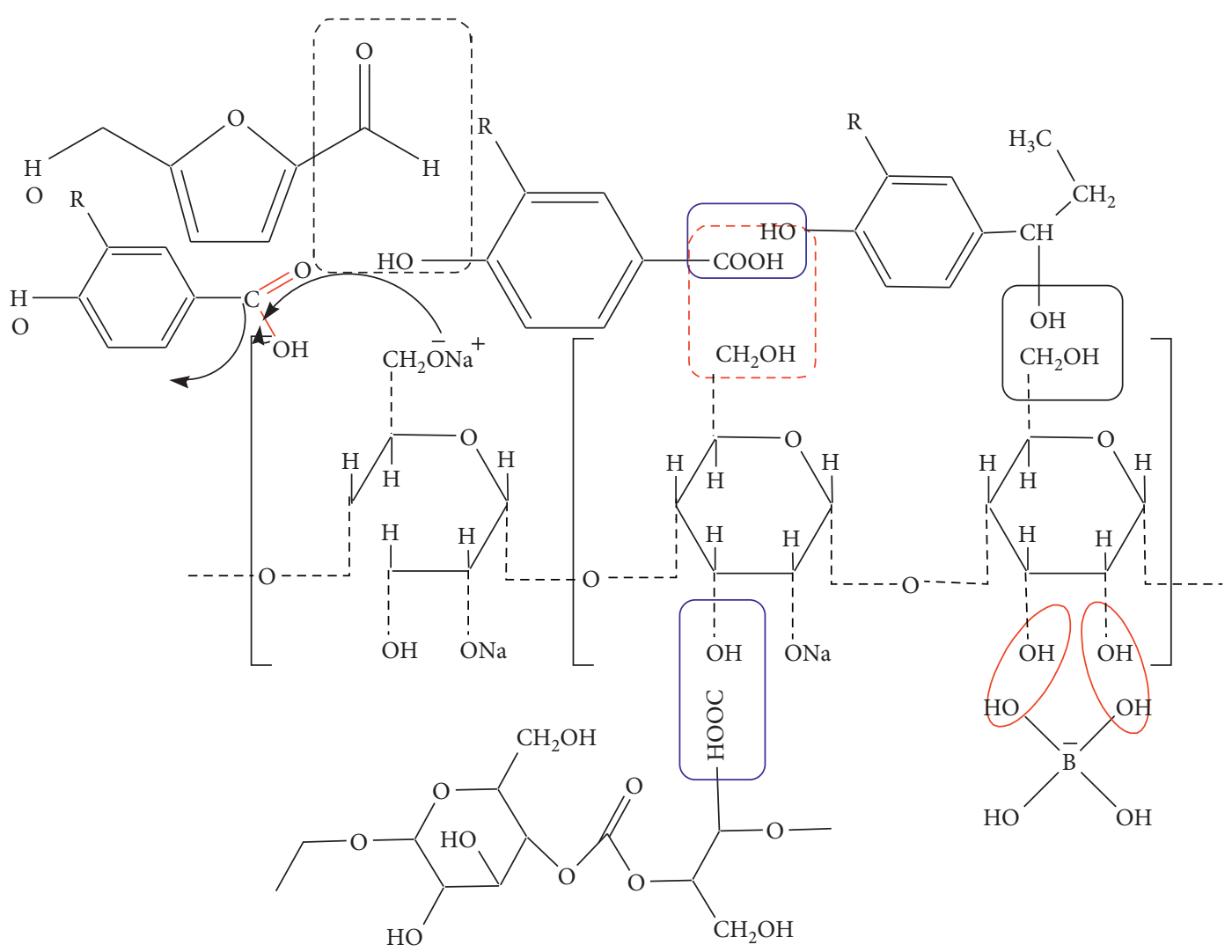

Scheme 4: Possible interaction mechanism between hydrolyzed starch and oxidized lignocellulose materials $[47,48]$.

2.2. Determination of Lignin Content. Lignin mass was determined through the Klason method [51]. One gram of oven-dried plant residues was weighed in triplicates and transferred to $100 \mathrm{ml}$ Pyrex beakers. $15 \mathrm{ml}$ of $72 \%$ sulfuric acid was cooled to $15^{\circ} \mathrm{C}$ and added gradually while continuously stirring and macerating the material with a glass rod. The mixture was kept in a water bath maintained at $20^{\circ} \mathrm{C}$ for two hours while being stirred continuously. The contents of the beaker were transferred to an Erlenmeyer flask containing $400 \mathrm{ml}$ of water. The resultant solution was topped to $575 \mathrm{ml}$ using water. The solution was boiled for four hours using a reflux condenser. The resultant mixture was allowed to settle overnight. The mixture was then filtered. The residue (lignin) was washed with distilled water and dried to constant weight in an oven at $105^{\circ} \mathrm{C}$. The lignin content was calculated from the oven-dried weight of the residue and reported as the average as shown in equation (3). The samples were labeled according to their source: lignin from rice husks (LRH), lignin from maize stalk (LMS), and lignin from sugarcane bagasse (LSCB).

$$
\text { Lignin content }(\%)=\frac{M_{\mathrm{b}}-M_{\mathrm{a}}}{M_{\mathrm{b}}} \times 100,
$$

where $M_{\mathrm{b}}$ is the oven-dried mass of the lignocellulose material before digestion and $M_{\mathrm{a}}$ is the oven-dried mass after digestion with acid.

2.3. Formulation of Particleboards. Formulation of particleboards was adopted from a method used for starch-lignin polymer preparation [52], but with improvements. $250 \mathrm{~cm}^{3}$ of $0.4 \mathrm{M}$ sodium hydroxide was preheated on an electric heater to $40^{\circ} \mathrm{C}$ in a $500 \mathrm{~cm}^{3}$ Pyrex beaker. $12.5 \mathrm{~g}$ of ground cassava starch was then added while continuously stirring the mixture. The temperature of the mixture was gradually raised and maintained between 55 and $60^{\circ} \mathrm{C}$ for 15 minutes. $0.2 \mathrm{~g}$ of borax was then added to the mixture while continuous stirring for 15 minutes. While being still hot, the hydrolyzed starch was transferred into a $1000 \mathrm{~cm}^{3}$ plastic beaker. $50 \mathrm{~g}$ ground and dried maize stalk was added into the hot hydrolyzed starch. The mixture was mechanically mixed and allowed to cure for two hours at room temperature. The mixture was then transferred into a metallic mold (internal dimensions: $300 \mathrm{~mm}$ by $100 \mathrm{~mm}$ by $20 \mathrm{~mm}$ ) with an internal lining of the polyethylene sheet. The resulting mixture was then compressed at a pressure of $6.5 \mathrm{Nmm}^{-2}$, at $30^{\circ} \mathrm{C}$ for 6 minutes, and then air-dried for 48 hours. The resultant molded composite material was dried to a constant mass using an oven maintained at $60^{\circ} \mathrm{C}$. The above procedure was repeated but using bagasse and rice husks separately in place of maize stalk. The resultant particleboards were labeled according to their lignocellulose materials used and the modified starch used. Those made from rice husks, maize stalk, and sugarcane bagasse were labeled PBR/HS, PBM/HS, and PBS/HS, respectively. Those formulated with rice husks, maize stalk, and sugarcane bagasse and oxidized starch (OS) as a binder were labeled PBR/OS, PBM/OS, and PBS/OS, respectively. Particleboards formulated with rice husks, maize stalk, and sugarcane bagasse and dextrinized starch 
(DS) as a binder were labeled PBR/DS, PBM/DS, and PBS/ DS. Particleboards formulated with urea-oxidized mix as a binder were labeled PBR/U/OS, PBM/U/OS, and PBS/U/OS, respectively.

2.4. Particleboard Property Evaluation. Physical (density, moisture content (MC), water absorption (WA), and thickness swelling (TS)) and mechanical (internal bonding (IB), modulus of rupture (MOR), and modulus of elasticity (MOE)) tests are important specifications for particleboards. They were measured for each formulated particleboard. Data were analyzed using Excel through data analysis (ANOVA: single factor) at the 95\% confidence level $(P \leq 0.05)$. Tukey's honestly significant difference (HSD) test was performed to further determine the significance level of the test properties.

2.5. Determination of Starch Content. Ten millilitres of $0.0304 \mathrm{M}$ potassium ferricyanide reagent were pipetted into clean $100 \mathrm{ml}$ Erlenmeyer flasks. $5.0 \mathrm{ml}$ of $2.5 \mathrm{M}$ sodium hydroxide was then added and mixed thoroughly while heating. Five drops of the dilute methylene blue indicator were added, and the resulting mixture was titrated with $2.0 \mathrm{ml}$ starch till the indicator changed to colourless solution. The titre readings were noted. Titration was repeated three times for each sample till concurrent titre values were obtained [53]. The starch content was calculated using the following equation:

$$
\frac{\operatorname{starch}(\mathrm{g})}{100 \mathrm{~g} \text { fresh weight }}=\frac{10^{a} \times 100^{b} \times 0.9^{c} \times 100}{T \times 2.0^{d} \times 1000},
$$

where $a$ is the titre obtained for the ferricyanide reagent, $b$ is the total volume of the hydrolyzed starch, $c$ is the factor used for converting sugar to starch (0.9), $T$ is the titre obtained for the hydrolyzed starch ( $\mathrm{ml})$, and $d$ is the weight of the cassava sample (g).

2.6. Testing. Physical tests for density, moisture content, water absorption, and thickness swelling were done. Mechanical tests for internal bonding, modulus of rupture, and modulus of elasticity were done. All tests were done using the standard test methods for evaluating properties of woodbased fibres and particle panel materials (ASTM D 1037-99). Raw materials and formulated boards were subjected to chemical analysis [54].

2.6.1. Density. Density of the particleboards was determined as a quotient of the difference between air-dried weight and air-dried volume:

$$
\operatorname{Density}\left(\mathrm{g} / \mathrm{cm}^{-3}\right)=\frac{W_{\mathrm{a}}-W_{\mathrm{o}}}{V_{\mathrm{o}}},
$$

where $W_{\mathrm{a}}$ is the air-dried weight and $V_{\mathrm{a}}$ is the air-dried volume.
Dimensions were taken with a micrometer screw, and weight was measured using a Mettler AJ150 analytical balance.

2.6.2. Moisture Content. The moisture content was obtained by determining the mass of the boards before oven-drying and after oven-drying:

$$
\text { moisture content }(\%)=\frac{W_{\mathrm{a}}-W_{\mathrm{o}}}{W_{\mathrm{o}}},
$$

where $W_{\mathrm{a}}$ is the air-dried weight and $W_{\mathrm{o}}$ is the oven-dried weight.

2.6.3. Water Absorption and Thickness Swelling. Water absorption and thickness swelling tests were done according to the ASTM standard method (ASTMD1037). Test pieces, $300 \mathrm{~mm} \times 50 \mathrm{~mm} \times 2 \mathrm{~mm}$, were cut and immersed in distilled water in a glass vessel and maintained at a temperature of $23^{\circ} \mathrm{C}$ for every 2 hours and 24 -hour interval. The weight and thickness of the samples were measured before and immediately after soaking within the 10-minute interval and used to calculate water absorption and thickness swelling.

2.6.4. Internal Bond Strength. Internal bond strength (IB) measurements were performed on $5 \mathrm{~cm} \times 5 \mathrm{~cm}$ square probes at a crosshead speed of $1.33 \mathrm{~mm} / \mathrm{min}$. IB was calculated using the following equation:

$$
\sigma t=W t b \times t,
$$

where $\sigma t=$ tensile stress $\left(\mathrm{N} / \mathrm{mm}^{2}\right), W t=$ failure tensile load $(\mathrm{N}), b=$ breadth of the specimen $(\mathrm{mm})$, and $t=$ thickness of the specimen.

2.6.5. Static Bending Test. Particleboards formulated were cut into various specimens according to the ASTM standard method (ASTM D1037-99). The rectangular $50 \mathrm{~mm}$ wide, $275 \mathrm{~mm}$ long, and $20 \mathrm{~mm}$ thick pieces were cut from each full particleboard. The pieces were used for thickness swelling and three-point-flex measurement of MOR and MOE, respectively. The $5.1 \mathrm{~cm} \times 5.1 \mathrm{~cm}$ square pieces were used for IB measurement. The mechanical properties were determined using an Instron testing machine (model 1122; Instron Corporation, Canton, MA) with the speed of the movable crosshead of $4 \mathrm{~mm} / \mathrm{min}$ for the TS test and $5 \mathrm{~mm} /$ min for three-point-flex and IB tests. The reported value is the average of triplicate measurements.

2.6.6. Fourier Transform Infrared (FTIR) Spectroscopy. Fourier transform infrared (FTIR) spectroscopy was used to characterize the type of functional groups existing in the raw materials and formulated particleboards. Pellets were prepared by mixing $5 \mathrm{mg}$ of powder of each sample type with $95 \mathrm{mg}$ of finely ground potassium bromide $(\mathrm{KBr})$ and pressing the mixture into pellets that are approximately $1 \mathrm{~mm}$ in thickness. Particleboards were maintained at $102^{\circ} \mathrm{C}$ for 24 hours in an oven. Materials were characterized by the 
attenuated total reflectance (ATR) mode using the potassium bromide $(\mathrm{KBr})$ disk (model Alpha 10054238 from Bruker instrument). Each spectrum was recorded from 4000 to $400 \mathrm{~cm}^{-1}$.

\subsection{Results and Discussion}

2.7.1. Lignin Content in Various Crop Residues. Results of the lignin content in the three lignocellulose materials are shown in Figure 1. Lignin from rice husks, maize stalk, and sugarcane bagasse is denoted as LRH, LMS, and LSCB, respectively.

The lignin content in sugarcane bagasse was more than that in rice husks and maize stalk. Maize stalk had the lowest percentage of lignin content among the three lignocellulose materials. This is within the range of 10 to 25 percent of the lignin content found in wood, a conventional lignocellulose material used in formulation of particleboards [55]. The lignin content determines the physical properties of the particleboard. These properties include water absorption and thickness swelling. Lignin added into a composite material during particleboard formulation reduces water absorption and thickness swelling [56]. Lignin contains a small number of hydroxyl groups that form hydrogen bonding with water [57]. The three lignocellulose materials are suitable for making particleboards. Sugarcane bagasse waste had been deposited for more than six months and thus had been concentrated naturally. Absence of cellulose and hemicellulose was due to decomposition. Maize stalk was collected immediately after harvest and thus had not been decomposed. Rice husks contain high percentage of silica and lignin content. Lignin obtained through the Klason method involves hydrolysis and solubilization of cellulose and hemicellulose from crop residues. Cellulose and hemicellulose compose the highest percentage in maize stalk with more than $88.6 \%$ on average. Rice husks contain an average of $15.9 \%$ of lignin compared to the total mass of the matrix. Rice husks contain high levels of silica in addition to lignin. This lowers their nutritional value to be used as animal fodder. Sugarcane bagasse contains high levels of lignin at an average of $21.5 \%$, making it less nutritive to be used as fodder.

2.7.2. Tukey's Statistical Analysis Results. One-dimensional ANOVA using the Tukey method for density, moisture content (MC), thickness swelling (TS), water absorption (WA), internal bonding (IB), modulus of rupture (MOR), and modulus of elasticity (MOE) is presented in Table 1.

2.7.3. Particleboard Densities. The average densities of particleboards are shown in Figure 2.

Statistically, no significant difference was observed between the particleboards formulated using rice husks (Table 1). Density of the boards ranged from 0.612 to $0.63 \mathrm{~g} /$ $\mathrm{cm}^{3}$. The densities of the particleboards made from the rice

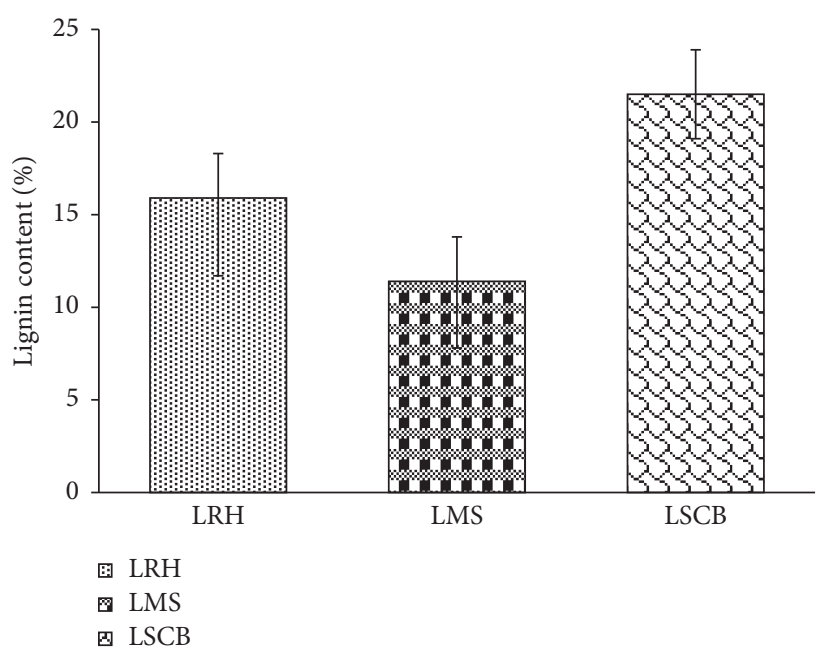

FIgURE 1: Lignin content in crop residues.

husks, maize stalk, and sugarcane bagasse ranged from $0.604 \mathrm{~g} / \mathrm{cm}^{3}$ to $0.627 \mathrm{~g} / \mathrm{cm}^{3}$. Densities formulated from rice husks and hydrolyzed starch were significantly different from those from dextrinized starch, oxidized starch, and urea-oxidized starch at $P=0.05$. The one-dimensional Tukey method showed $P>0.05$ between PBR/DS, PBR/OS, and $\mathrm{PBR} / \mathrm{U} / \mathrm{OS}$. Comparing the $P$ value of the three with $\mathrm{PBR} / \mathrm{HS}$ showed $P<0.05$. There is a significant difference between the particleboards formulated from maize stalk and various chemically modified starch, $P>0.05$. Similar trends were also observed in particleboards formulated from sugarcane bagasse and cassava-based binders, $P>0.05$. Results showed the synthesized particleboards fell in the category of low density which is $d<0.640$ [58]. Research investigated by formulation of composite boards from oil palm trunk stems showed densities that ranged from 0.441 to $0.597 \mathrm{~g} / \mathrm{cm}^{3}$ [59].

Particleboards formulated using maize stalk and sugarcane bagasse showed a significant difference, as shown in Table 1. Particleboards made from dextrinized starch had the highest densities across the three lignocellulose materials. Densities of the composite material are affected by the interaction between the lignocellulose materials and the binder. An increase in the interaction reduces the voids in the resulting blend, resulting in higher density. Dextrinized starch contains a high number of hydroxyl groups. During particleboard formulation, the hydroxyl groups are involved in esterification, leading to the formation of covalent bonding and others through hydrogen bonding. This reduces the spaces between the blended materials, thus increasing the density. Hydrolyzed starch contains hydroxyl groups that are partially converted into sodium salt [60] as follows:

$$
\mathrm{St}-\mathrm{OH}+\mathrm{NaOH} \leftrightarrow \mathrm{St}-\mathrm{ONa}+\mathrm{H}_{2} \mathrm{O}
$$

This minimizes the interaction between lignocellulose materials and the modified starch. These result in formation of voids that increase the volume of the composite material, thus reducing the density of the particleboards. 
TABle 1: Average values of physical and mechanical properties of particleboards formulated.

\begin{tabular}{|c|c|c|c|c|c|c|c|}
\hline \multirow{2}{*}{ Boards } & \multicolumn{4}{|c|}{ Physical properties } & \multicolumn{3}{|c|}{ Mechanical properties } \\
\hline & Density $\left(\mathrm{g} / \mathrm{cm}^{3}\right)$ & $\mathrm{MC}(\%)$ & WA $(\%)$ & TS & IB & MOR & MOE \\
\hline PBR/HS & $0.612^{\mathrm{a}}$ & $9.587^{\mathrm{a}}$ & $76.33^{\mathrm{a}}$ & $19.32^{\mathrm{a}}$ & $1.613^{\mathrm{a}}$ & $13.630^{\mathrm{a}}$ & $2651.61^{\mathrm{a}}$ \\
\hline $\mathrm{PBR} / \mathrm{DS}$ & $0.623^{\mathrm{a}}$ & $9.700^{\mathrm{b}}$ & $74.67^{\mathrm{a}}$ & $20.63^{\mathrm{b}}$ & $1.623^{\mathrm{a}}$ & $13.553^{\mathrm{a}}$ & $2875.67^{\mathrm{b}}$ \\
\hline $\mathrm{PBR} / \mathrm{OS}$ & $0.622^{\mathrm{a}}$ & $9.593^{\mathrm{c}}$ & $64.67^{\mathrm{b}}$ & $18.59^{\mathrm{c}}$ & $1.657^{\mathrm{b}}$ & $13.770^{\mathrm{b}}$ & $2806.67^{\mathrm{c}}$ \\
\hline $\mathrm{PBR} / \mathrm{U} / \mathrm{OS}$ & $0.621^{\mathrm{a}}$ & $9.487^{\mathrm{d}}$ & $68.61^{c}$ & $19.12^{\mathrm{d}}$ & $1.710^{\mathrm{c}}$ & $14.323^{\mathrm{c}}$ & $2891.67^{\mathrm{d}}$ \\
\hline $\mathrm{PBM} / \mathrm{HS}$ & $0.604^{\mathrm{a}}$ & $9.577^{\mathrm{a}}$ & $81.33^{\mathrm{a}}$ & $22.77^{\mathrm{a}}$ & $2.220^{\mathrm{a}}$ & $14.380^{\mathrm{a}}$ & $2508.34^{\mathrm{a}}$ \\
\hline $\mathrm{PBM} / \mathrm{DS}$ & $0.622^{\mathrm{b}}$ & $9.843^{\mathrm{b}}$ & $83.87^{\mathrm{a}}$ & $23.43^{\mathrm{b}}$ & $2.367^{\mathrm{b}}$ & $13.960^{\mathrm{b}}$ & $2364.20^{\mathrm{b}}$ \\
\hline $\mathrm{PBM} / \mathrm{OS}$ & $0.621^{\mathrm{c}}$ & $9.763^{\mathrm{c}}$ & $72.67^{\mathrm{b}}$ & $19.31^{\mathrm{c}}$ & $2.343^{\mathrm{c}}$ & $14.720^{\mathrm{c}}$ & $2672.27^{\mathrm{c}}$ \\
\hline $\mathrm{PBM} / \mathrm{U} / \mathrm{OS}$ & $0.615^{\mathrm{a}}$ & $9.593^{\mathrm{d}}$ & $78.68^{\mathrm{c}}$ & $19.44^{\mathrm{d}}$ & $2.370^{\text {bd }}$ & $14.830^{\mathrm{d}}$ & $2716.57^{\mathrm{d}}$ \\
\hline $\mathrm{PBS} / \mathrm{HS}$ & $0.608^{\mathrm{a}}$ & $9.543^{\mathrm{a}}$ & $66.67^{\mathrm{a}}$ & $18.94^{\mathrm{a}}$ & $1.720^{\mathrm{a}}$ & $13.880^{\mathrm{a}}$ & $3175.71^{\mathrm{a}}$ \\
\hline $\mathrm{PBS} / \mathrm{DS}$ & $0.627^{\mathrm{b}}$ & $9.770^{\mathrm{b}}$ & $69.27^{\mathrm{b}}$ & $19.88^{\mathrm{a}}$ & $1.677^{\mathrm{a}}$ & $13.630^{\mathrm{b}}$ & $2907.68^{b}$ \\
\hline PBS/OS & $0.619^{\mathrm{ab}}$ & $9.567^{\mathrm{a}}$ & $61.33^{c}$ & $18.23^{\mathrm{b}}$ & $1.820^{\mathrm{b}}$ & $14.134^{\mathrm{c}}$ & $3229.08^{c}$ \\
\hline $\mathrm{PBS} / \mathrm{U} / \mathrm{OS}$ & $0.611^{\mathrm{ab}}$ & $9.553^{\mathrm{c}}$ & $71.04^{\mathrm{d}}$ & $18.46^{\mathrm{c}}$ & $1.950^{\mathrm{c}}$ & $14.320^{\mathrm{d}}$ & $3329.93^{\mathrm{d}}$ \\
\hline
\end{tabular}

Same letters show no significant difference, while different letters show significant difference from each other in the Tukey test at the $5 \%$ significance level.

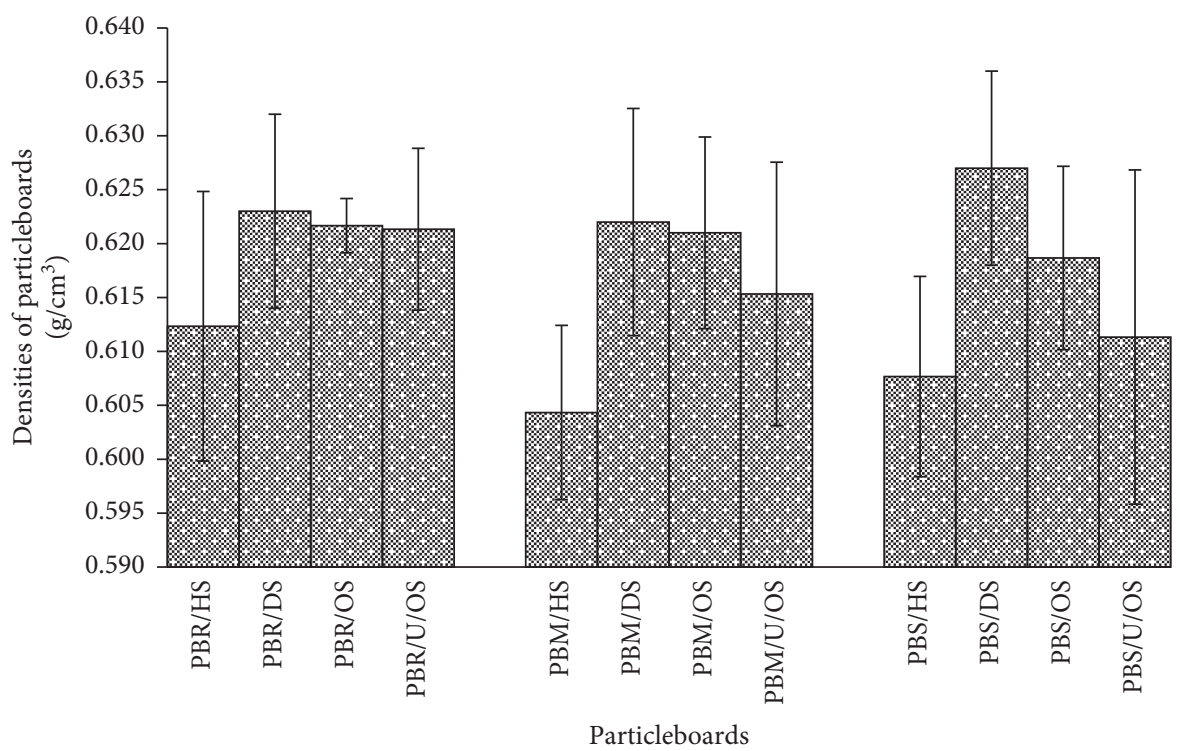

Figure 2: Average densities of particleboards and their standard deviation as error bars.

2.7.4. Moisture Content. Figure 3 shows the moisture content of the particleboards.

Moisture influences the density of particleboard as it serves as a means of heat transfer. Heat transfer from composite mat faces to the composite mat core helps in the curing of the binder [61]. Particleboards with high moisture content showed highest densities. High moisture content affects the mechanical properties such as the modulus of rupture. All those boards with high moisture content showed lowest MOR. Particleboards from maize stalk bonded with dextrinized starch had the highest amount of moisture content. Dextrinization involves cleavage of molecular chains in starch granules to afford smaller structural units [62]. This results in the increase of surface area of the lignocellulose material which exposes the hydroxyl group that interacts with water vapour in the atmosphere. The moisture content in lignocellulose materials is controlled by the available hydroxyl group content and their accessibility [63]. During oxidation of starch, hydroxyl groups are converted to aldehydes and carboxylic groups [64].

Aldehydes and carboxylic groups are used during esterification. The hydroxyl groups are therefore reduced in the process of particleboard formulation. Hydroxyl groups transformed into aldehydes and carboxylic groups are used in formation of bondage between the modified starch and the lignocellulose material. Rice husks bonded with oxidized starch and urea showed the lowest moisture content. Sodium hydroxide used reacts with silica to form silicic acid. Silicic acid is an inorganic adhesive that undergoes condensation by cross-linking and dehydration to yield less hydrated silicon dioxide phases. Porosity of the particleboard made from maize stalk is higher than that of the particleboard made from sugarcane bagasse and rice husks [65].

2.7.5. Water Absorption. Water absorption of the particleboards is shown in Figure 4. 


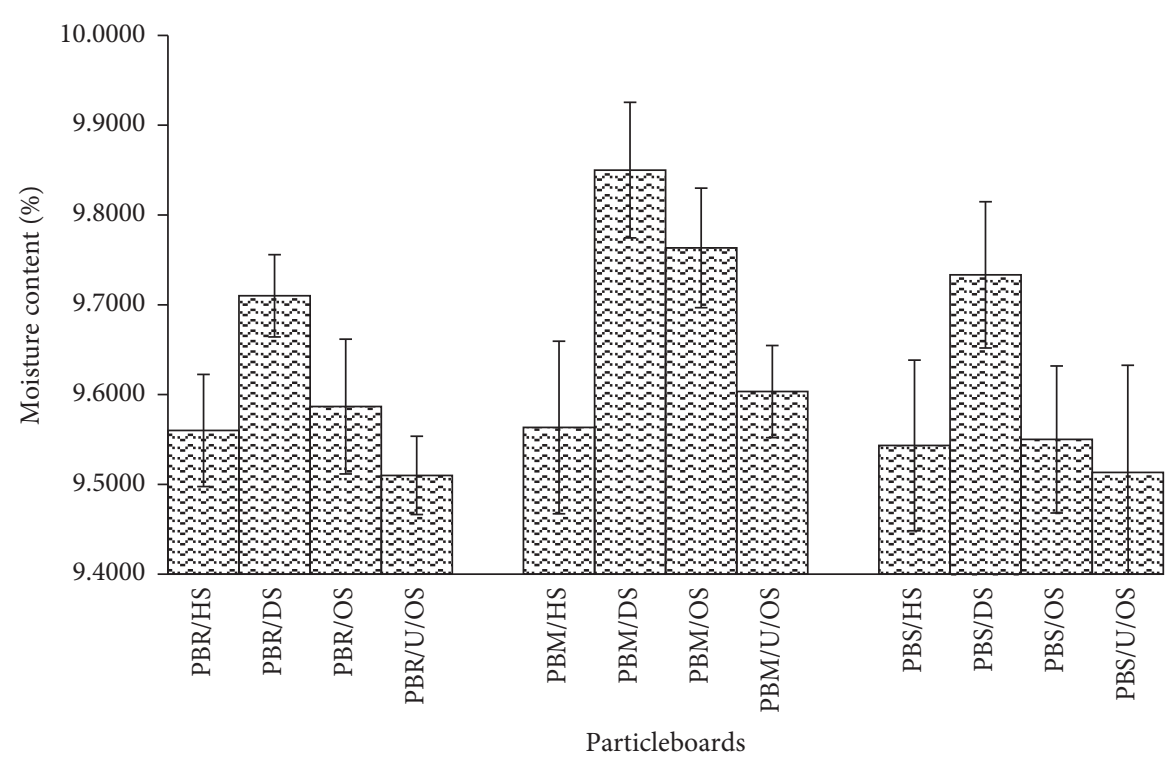

FIGURE 3: Moisture content of particleboards.

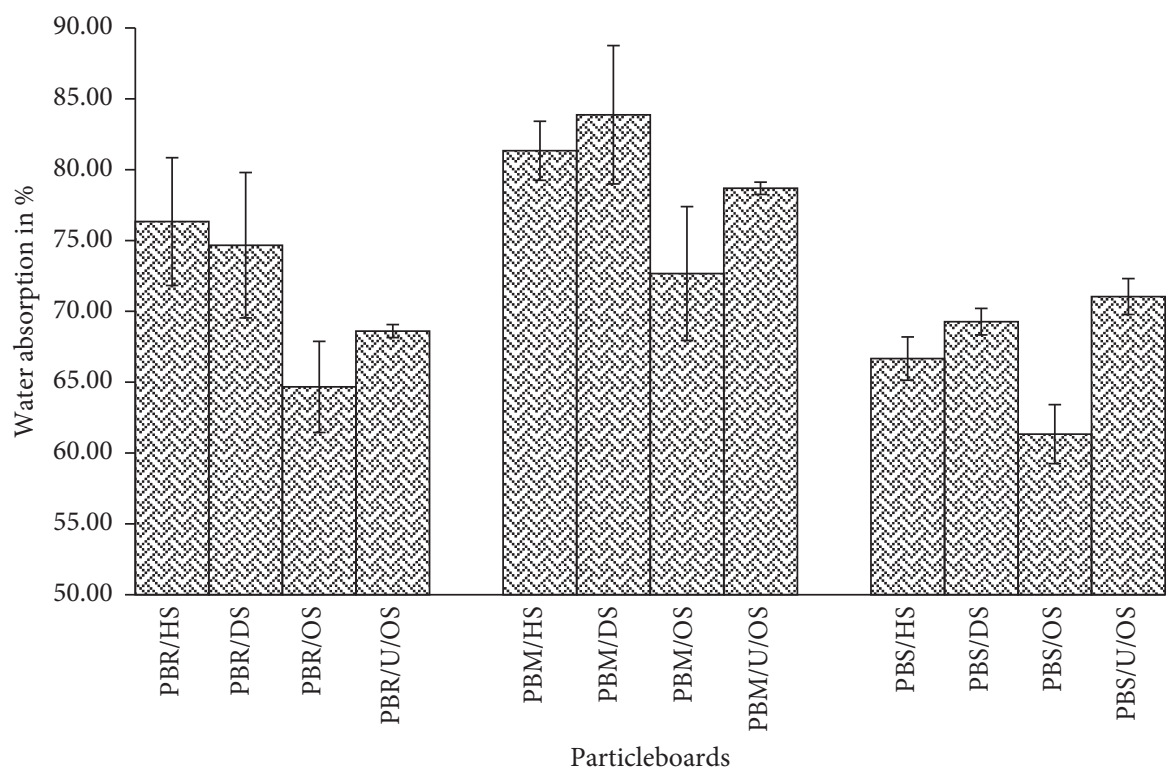

FIGURE 4: Water absorption (WA) of synthesized particleboards.

Particleboards formulated with maize stalk and dextrinized starch as a binder had the highest water absorption of $83.87 \%$. Maize stalk contains high content of cellulose and hemicellulose materials. Cellulose and hemicellulose contain high hydroxyl groups. Hydroxyl groups influence the physical properties of the composite materials formulated. Hydroxyl groups form hydrogen bonding with water, thus absorbing a lot of water. Particleboard with a high lignin content of $21.5 \%$ showed reduction in water absorption. Lignin is a hydrophobic material and reduces the WA of particleboards [56]. The initial high water absorption rate was due to diffusion through capillaries, vessels, and cellular walls of crop residues.
Moisture movement was restricted within the matrix. Water moves easily into large cavities of maize stalk than into small cavities of sugarcane bagasse [66]. Here, water already had enough time to permeate through the entire panel structure, and lignocellulose materials being lowdensity residues, a larger number of particles are needed to compose the medium-density particleboards. This allows more hygroscopic sites for water to bind. Maize stalk contains holocellulose that contains polyoses which have hygroscopic sites that promote higher WA [67]. It has been suggested that the furniture particleboard requires less than 60\% long-term water absorption (ASTM D 103799). All particleboards made in this study showed higher 
water absorption than the maximum allowed by the ASTM D 1037-99 standard. This challenge was managed by addition of water repellants such as paraffin and phenolic resins during particleboard formulation [35]. All particleboards showed $P<0.05$, showing there was a significant difference between different cassava-based binders.

2.7.6. Thickness Swelling. Particleboards formulated showed thickness swelling as in Figure 5.

Thickness swelling showed a direct relationship to the results obtained on water absorption. Particleboards made from maize stalks bound with dextrinized starch showed the highest TS of $23.43 \%$. This is attributed to the presence of the cellulose material in maize stalk. PBM/DS showed the highest thickness swelling of $27.08 \%$, and PBS/OS showed the least at 18.23 and PBR/HS at $19.32 \%$ and $25.59 \%$, respectively.

Particleboards based on the ASTM D 1037-99(1999) standard should have a maximum thickness swelling value of $25 \%$ for general uses [68], and according to the US Standard ANSI/A208.1, the average maximum thickness swelling value is $8 \%$ (for $2 \mathrm{~h}$ immersion) [69]. The average TS values of all the specimens analyzed meet this minimum requirement for general uses. Pores accommodate absorbed water, resulting in swelling of the added lignocellulose materials. This phenomenon leads to more moisture buildup in the maize stalk cell wall (fibre swelling) and also in the fibre-adhesive interface. This is responsible for the changes in the dimension of particleboards, particularly in the thickness and the linear expansion due to reversible and irreversible swelling of the boards [70]. This is attributed to the presence of the hydroxyl group content formed during hydrolysis by sodium hydroxide. The amount of the hydroxyl group depends on the concentration of the lignin content. Particleboards formulated with rice husks and maize stalk did not show any significant difference, $P<0.05$, while those made from sugarcane bagasse showed $P>0.05$.

\subsubsection{Chemical Analysis for the Particleboards}

(1) Elemental Analysis. The results in Table 2 show chemical analysis for $\mathrm{Na}, \mathrm{Zn}, \mathrm{Ca}$, and $\mathrm{Mg}$ in crop residues and cassava starch.

Sodium ions $\left(\mathrm{Na}^{+}\right)$were low in both lignocellulose materials and starch. Sodium enables the curing process of the cassava adhesive. Treatment of the starch with sodium hydroxide increased the concentration of the sodium ions. Zinc is involved in the synthesis and breakdown of carbohydrates. Chemical additives containing zinc and magnesium influence the bonding strength of the particleboards [71]. $\mathrm{Zn}^{2+}$ improves starch granule dissolution as it penetrates into the inner structure of the starch granules and weakens the intra- and intermolecular hydrogen bonds. This results in disruption of the crystalline nature of the starch [72]. $\mathrm{Ca}^{2+}$ influences the physicochemical properties of the starch granules and changes morphological, vibrational, mechanical, and pasting properties [73]. $\mathrm{Ca}^{2+}$ ions influence the elastic and plastic regions of the hydrogel. $\mathrm{Mg}^{2+}$ is a plasticizer and increases the swelling and solubility index [72]. Metal oxides and hydroxides such as $\mathrm{MgO}$ and $\mathrm{Mg}(\mathrm{OH})_{2}$ control the acidity of the reaction mixture.

(2) Fourier Transform Infrared (FTIR) Spectroscopy. Figure 6 shows several major absorption bands for native cassava starch, rice husks, sugarcane bagasse, and PBM/OS board.

A major peak was found at $3414.06 \mathrm{~cm}^{-1}$ which was attributed to the presence of intramolecular hydrogenbonded hydroxyl groups in single bridge compounds. Another peak was observed at $1626.98 \mathrm{~cm}^{-1}$ which was for $-\mathrm{OH}$ bending. The peaks at $2484.36 \mathrm{~cm}^{-1}$ and $1362.73 \mathrm{~cm}^{-1}$ corresponded to C-H bending. A peak was observed at wavenumber $1229.64 \mathrm{~cm}^{-1}$ that corresponds to $\mathrm{C}=\mathrm{O}$ vibration and at $1102.34 \mathrm{~cm}^{-1}$ that corresponds to $\mathrm{C}-\mathrm{O}$ stretching. There were major functional group transformations from rice husks and gelatinized cassava starch, leading to reduction in the peak size at wavenumber $3414.06 \mathrm{~cm}^{-1}$, - $\mathrm{OH}$ stretching, and increase in $2484.36 \mathrm{~cm}^{-1}$ for C-O. Reduction in the $\mathrm{OH}$ peak was attributed to formation of esters and hence the formation of $\mathrm{C}-\mathrm{O}$ in $\mathrm{C}-\mathrm{O}-\mathrm{C}$. The $-\mathrm{OH}$ spectra that remained can be attributed to the presence of sodium hydroxide used in the pretreatment of the lignocellulose matrix, water formed through condensation polymerization, and also boric acid formed during hydrolysis of borax in sodium hydroxide. The $\mathrm{C}-\mathrm{H}$ peak increased because of the addition of $\mathrm{C}-\mathrm{H}$ functional groups from both cassava and lignocellulose matrices. Peaks observed at $1150 \mathrm{~cm}^{-1}$ and $950 \mathrm{~cm}^{-1}$ were attributed to $\mathrm{B}-\mathrm{O}-\mathrm{H}$ because of hydrolysis of borax.

\subsubsection{Mechanical Properties}

(1) Internal Bond. Particleboards formulated from rice husks, maize stalk, and sugarcane bagasse with various binders showed internal bond (IB), as illustrated in Figure 7 .

Particleboard formulated with maize stalk and dextrinized starch showed the highest internal bonding of $2.367 \% \mathrm{~N} / \mathrm{mm}^{2}$. Maize stalk contains low percentage of lignin and high content of cellulose and hemicellulose. The hemicellulose content increases the fibre joint strength. The bonding of fibres is described by the bonded area and the bonding strength between fibres. The high density of particleboards made from maize stalk and dextrinized starch increases fibre-to-fibre bonding strength. Density results in the improvement of fibre-to-fibre bonding [74]. Maize stalk was treated with sodium hydroxide that increases the flexibility of fibres. Sodium hydroxide increases the flexibility of lignin in maize stalk. This changes the surface morphology of lignin that influences the specific bond strength and cohesiveness in the composite material. Cellulose has been used in reinforcement of internal bondage of the composite material [75]. Cellulose provides more hydroxyl groups that are involved in chemical 


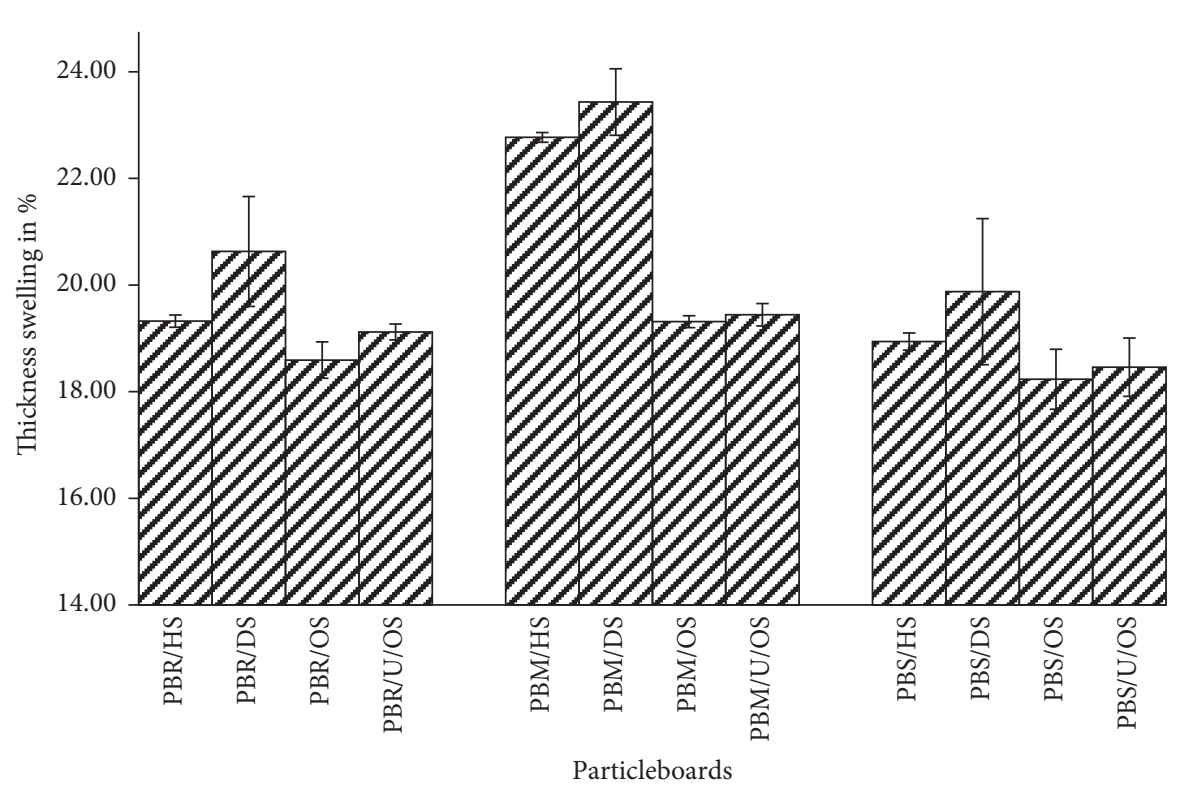

FIgURE 5: Thickness swelling (TS) of the particleboards.

TABLE 2: Chemical analysis for lignocellulose materials and cassava starch.

\begin{tabular}{lcccc}
\hline & $\mathrm{Na}$ & $\mathrm{Zn}$ & $\mathrm{Ca}$ & $\mathrm{Mg}$ \\
\hline Rice husk & $0.001 \pm 0.001$ & $0.005 \pm 0.001$ & $1.029 \pm 0.012$ & $0.001 \pm 1.841$ \\
Maize stalk & $0.002 \pm 0.001$ & $0.055 \pm 0.001$ & $8.021 \pm 0.540$ & $17.085 \pm 2.842$ \\
Bagasse & $0.002 \pm 0.003$ & $0.012 \pm 0.001$ & $3.893 \pm 0.350$ & $12.862 \pm 2.877$ \\
Cassava starch & $0.003 \pm 0.002$ & $0.038 \pm 0.021$ & $10.087 \pm 0.321$ & $0.001 \pm 0.217$ \\
\hline
\end{tabular}

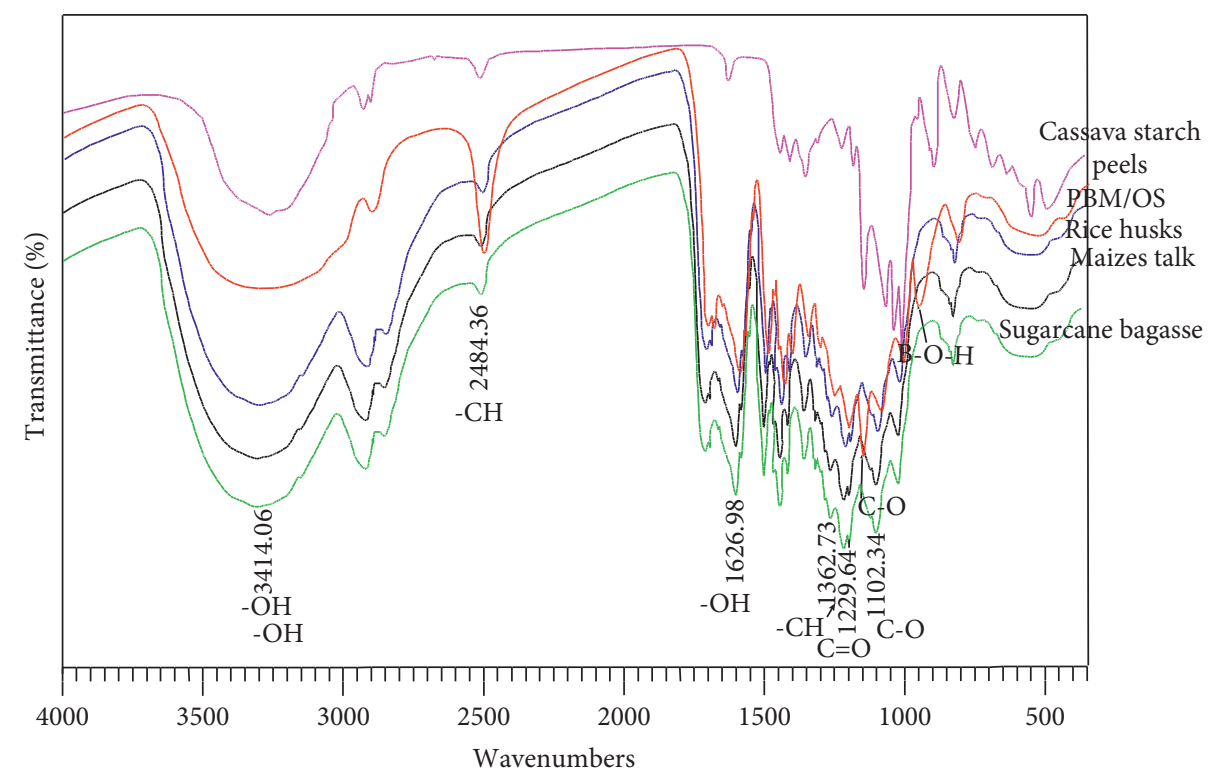

FIgURE 6: FTIR spectra for cassava starch, rice husks, sugarcane bagasse, and PBM/OS board.

reactions between crop residues and the starch-based binder [76].

Particleboards formulated from rice husks showed the lowest internal bonding of $1.613 \mathrm{~N} / \mathrm{mm}^{2}$. This is attributed to low hemicellulose content in the rice husks that reinforce the bondage in composite materials. The lignin content in rice husks was higher than that in maize stalk. This implies that the cellulose content is lower in rice husks. Reduction in the 


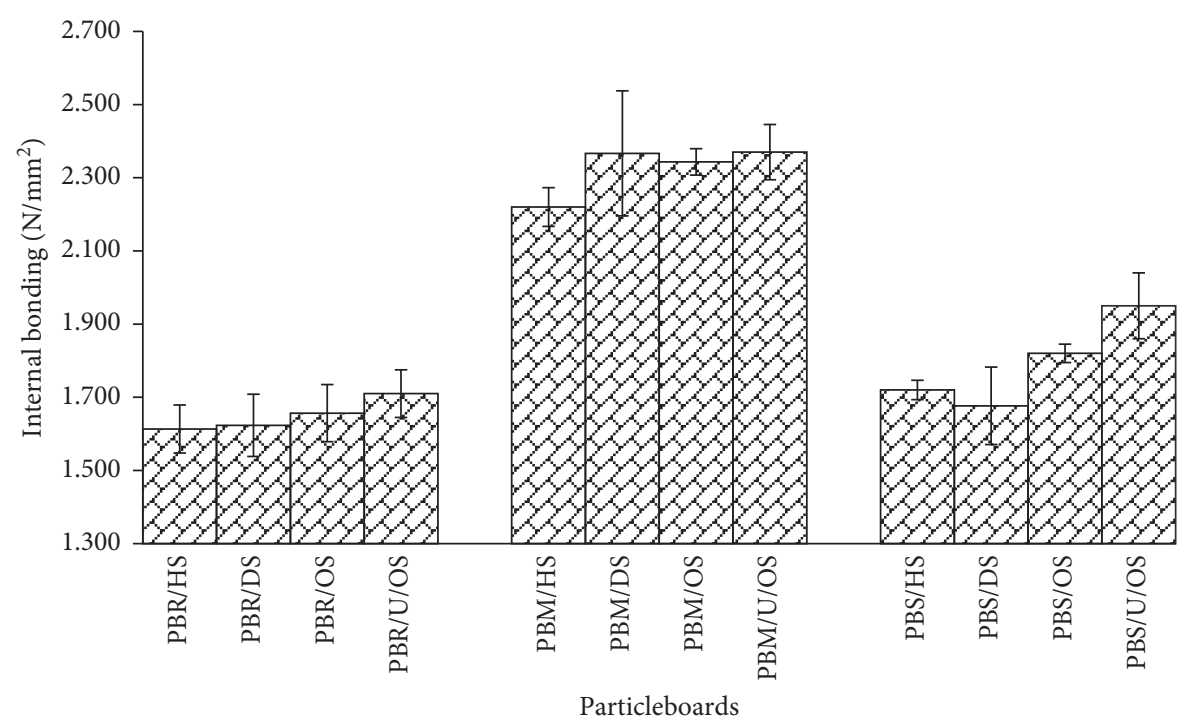

FIGURE 7: IB of the particleboards formulated using rice husks, maize stalk, and sugarcane bagasse.

cellulose and hemicellulose content reduced the amount of hydroxyl groups that influences cohesion between components of the particleboard.

Particleboards met minimum requirements of IB between 0.24 and $0.4 \mathrm{~N} / \mathrm{mm}^{2}$ for both general use and furniture manufacturing based on the European standard EN 312:2010 [77]. They also they met the minimum requirements of $0.60 \mathrm{~N} / \mathrm{mm}^{2}$ based on ANSI A208 for interior applications, as shown in Figure 7. The density of the particleboards is directly related to internal bonding. Particleboards made from maize stalk had the highest IB. This is attributed to the cross-linking of cellulose, hemicellulose, and lignin. At low temperatures of $40^{\circ} \mathrm{C}$, the density greatly improved the IB [78]. The higher the density the more the resin was used. Findings have been reported on the effect of the increase of surface area on strength properties [79], although the increase in surface area decreases the internal bonding.

\subsubsection{Static Bending Test}

(1) Modulus of Rupture (MOR). Modulus of rupture of particleboards formulated in this study is presented in Figure 8.

Particleboard is a random blend of lignocellulose materials that require no orientation during board formulation. In this study, composite materials were put in a mold with no bias towards the forming direction expected. Tests for the MOR and MOE properties were taken parallel and perpendicular to the forming directions. Analysis of the test data revealed a significant difference between samples from the parallel and perpendicular directions. Particleboards from maize stalk showed the highest MOR of more than $13.96 \mathrm{~N} / \mathrm{mm}^{2}$. MOR is influenced by the cross-linking of the lignocellulose materials with the binder and the particle geometry. Maize stalk contains cellulose and hemicellulose that provide hydroxyl groups that underwent esterification with carboxylic groups from oxidized starch. Esterification leads to cross-linking of starch and lignocellulose materials, hence increasing the MOR. A covalent bond is formed during the esterification process which is a strong bond. Reddy and Yang [80] have shown that a hydroxyl group and a carboxyl group react to form cross-linked molecules. In their study, the hydroxyl group from starch was cross-linked with the carboxylic group from citric acid. The findings showed improvement of the performance of bondage in composite materials [80].

Low-density particleboards formulated exceeded the minimum requirements of $2.8 \mathrm{~N} / \mathrm{mm}^{2}$ for interior applications based on ASNI 208.2-2009. Rice husks contain very high percentages of silica. Silica reacts with sodium hydroxide to form sodium silicate which is an adhesive [81].

(2) Modulus of Elasticity (MOE). Figure 9 shows the average MOE of particleboards made from rice husk, maize stalk, and sugarcane bagasse.

Particleboards made from sugarcane bagasse had the highest MOE of $3175.71 \mathrm{~N} / \mathrm{mm}^{2}$, those from rice husks had $2647.23 \mathrm{~N} / \mathrm{mm}^{2}$, and those from maize stalk had $2508.34 \mathrm{~N} / \mathrm{mm}^{2}$. All low-density boards attained the MOE of $1241 \mathrm{~N} / \mathrm{mm}^{2}$ based on ASNI 208.2-2009 for interior applications. Trends in MOE are similar to those of MOR where there is no significant difference between particleboards formulated from rice husks. In addition, there was no significant difference among particleboards formulated with maize stalk and sugarcane bagasse. Low-density particleboards formulated exceeded the minimum MOR of $500 \mathrm{~N} / \mathrm{mm}^{2}$. 


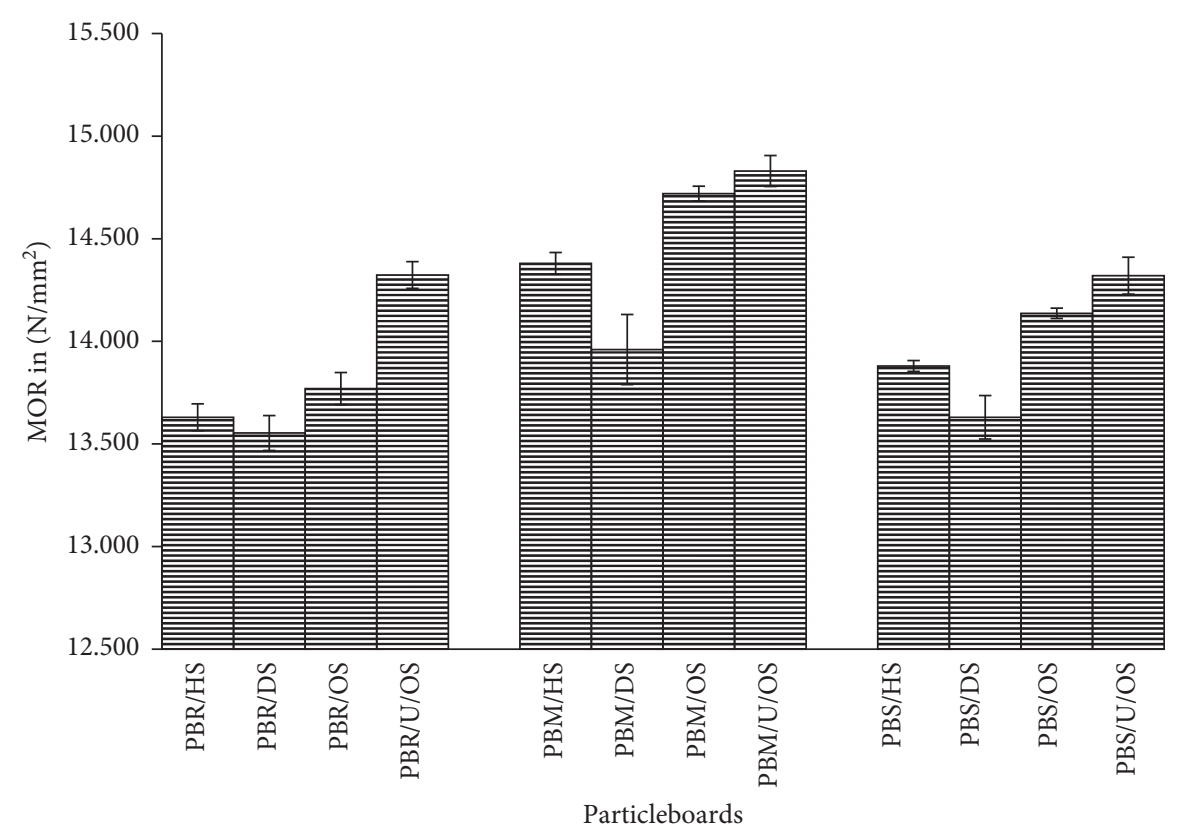

Figure 8: MOR of the three particleboards formulated in this study.

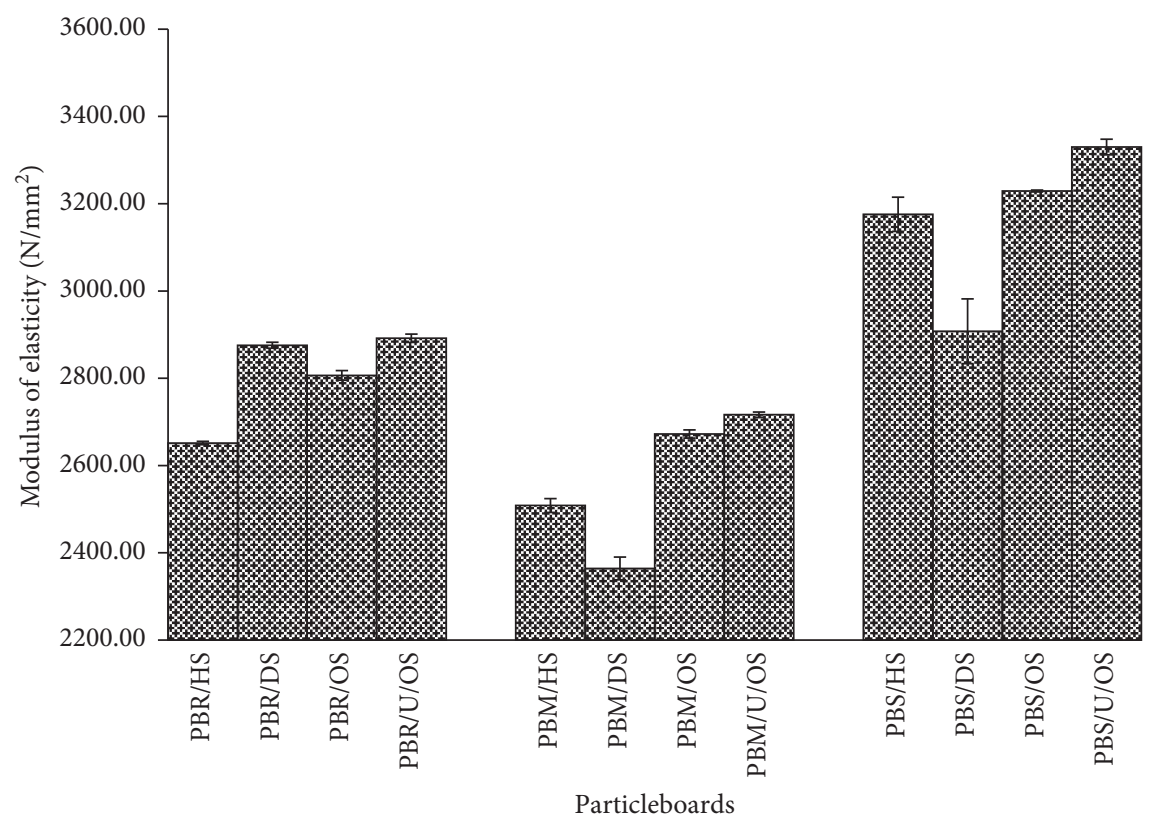

Figure 9: MOE of the three formulated particleboards.

\section{Conclusion}

Chemical treatment of the lignocellulose material and starch led to the formation of essential functional groups used in esterification. This resulted in compatibility of lignocellulose materials and starch materials used in formulation of composite materials. Composite materials were molded to form the particleboard. The particleboard formulated showed high water absorption and thickness swelling. The results showed that mechanical properties of the formulated low-density particleboards exceeded the requirements of American Society for Testing and
Materials (ANSI 208.1 1999). Furthermore, all physical properties, except water absorption and thickness swelling, met the ANSI 208.11999 standards. Water absorption and thickness swelling were due to a high number of hydroxyl groups. Hydroxyl groups formed hydrogen bonding with water, making the composite material interact with water. Reduction of hydroxyl groups through chemical modification resulted in introduction of carboxylate groups that formed a covalent bond between the lignocellulose material and the starch binder. Particleboards formulated showed characteristics of low density. From this study, it was apparent that rice husks, sugarcane bagasse, and maize 
stalk formulate low-density particleboards for interior housing applications.

\section{Data Availability}

The data used to support the findings of this study are available from the corresponding author upon request.

\section{Conflicts of Interest}

The authors declare that there are no conflicts of interest regarding the publication of this paper.

\section{Acknowledgments}

The authors acknowledge the immense support from the University of Embu for availing their chemistry laboratory for research; the Ministry of Infrastructure and Roads, where most physical and mechanical properties were investigated; the Ministry of Geology and Mines for XRF analysis; and Kenyatta University, where FTIR spectroscopy analysis was performed.

\section{References}

[1] S. R. Collinson and W. Thielemans, "The catalytic oxidation of biomass to new materials focusing on starch, cellulose and lignin," Coordination Chemistry Reviews, vol. 254, no. 15-16, pp. 1854-1870, 2010.

[2] K. S. Jitendra, S. Reetu, and T. Lakshmi, "Lignocellulosic agriculture wastes as biomass feedstocks for second-generation bioethanol production: concepts and recent developments," Journal for Biotechnology, vol. 5, no. 4, pp. 337-353, 2015.

[3] E. Papadopoulou and C. Konstantinos, "2 particleboards from agricultural lignocellulosics and biodegradable polymers prepared with raw naterials from natural resources," in Natural Fiber-Reinforced Biodegradable and Bioresorbable Polymer Composites, C. C. Centre, Ed., pp. 19-30, Elsevier, St Louis, MO, USA, 2017.

[4] P. Mona and S. Hitesh, "Greenhouse gas emissions from the field burning of crop residues for the state of Gujarat," International Association of Biologicals and Computational Digest, vol. 1, pp. 47-59, 2016.

[5] T. H. Yang, C. J. Lin, S. Y. Wang, and M. J. Tsai, "Characteristics of particleboard made from recycled wood-waste chips impregnated with phenol formaldehyde resin," Journal on Building and Environment, vol. 42, pp. 189-195, 2013.

[6] H. B. Klinke, B. K. Ahring, A. S. Schmidt, and A. B. Thomsen, "Characterization of degradation products from alkaline wet oxidation of wheat straw," Bioresource Technology, vol. 82, no. 1, pp. 15-26, 2002.

[7] M. B. Hocking and J. P. Crow, "On the mechanism of alkaline hydrogen peroxide oxidation of the lignin model p-hydroxyacetophenone," Canadian Journal of Chemistry, vol. 72, no. 4, pp. 1137-1142, 1994.

[8] A. Potthast, T. Rosenau, and P. Kosma, "Analysis of oxidized functionalities in cellulose," Journal for Polymer Science, vol. 205, pp. 1-48, 2006.

[9] S. Narkchamnan and C. Sakdaronnarong, "Thermo-molded biocomposite from cassava starch, natural fibers and lignin associated by laccase-mediator system," Carbohydrate Polymers, vol. 96, no. 1, pp. 109-117, 2013.
[10] X. Erdocia, R. Prado, M. Á. Corcuera, and J. Labidi, "Base catalyzed depolymerization of lignin: influence of organosolv lignin nature," Biomass and Bioenergy, vol. 66, pp. 379-386, 2014.

[11] S. Lepifre, S. Baumberger, B. Pollet, F. Cazaux, X. Coqueret, and C. Lapierre, "Reactivity of sulphur-free alkali lignins within starch films," Industrial Crops and Products, vol. 20, no. 2, pp. 219-230, 2004.

[12] H. S. S. Shekar and M. Ramachandra, "Green composites: a review," Materials Today: Proceedings, vol. 5, no. 1, pp. 2518-2526, 2018.

[13] S. Baumberger, C. Lapierre, B. Monties, and G. D. Valle, "Use of kraft lignin as filler for starch films," Journal on Polymer Degradation and Stability, vol. 59, no. 1-3, pp. 273-277, 2010.

[14] M. Irle, C. Belloncle, B. L. R. Guezguez, and R. Chauvin, "An investigation of a 'green' extender for synthetic adhesives," in Proceedings: ARBORA Conference, pp. 20-21, Bordeaux, France, November 2008.

[15] S. Kim, "The reduction of formaldehyde and VOCs emission from wood-based flooring by green adhesive using cashew nut shell liquid (CNSL)," Journal of Hazardous Materials, vol. 182, no. 1-3, pp. 919-922, 2010.

[16] Y. Liu and K. Li, "Chemical modification of soy protein for wood adhesives," Macromolecular Rapid Communications, vol. 23, no. 13, pp. 739-742, 2002.

[17] K. F. Patel, H. U. Mehta, and H. C. Srivastava, "Kinetics and mechanism of oxidation of starch with sodium hypochlorite," Journal of Applied Polymer Science, vol. 18, no. 2, pp. 389-399, 1974.

[18] D. Gumul, H. Gambuś, and M. Gibiński, "Air oxidation of potato starch over zinc (II) catalyst," Carbohydrate Polymers, vol. 42, no. 1, pp. 45-50, 2014.

[19] Z. Qiao, J. Gu, S. Lv, J. Cao, H. Tan, and Y. Zhang, "Preparation and properties of normal temperature cured starchbased wood adhesive," Journal on BioResources, vol. 11, pp. 4839-4849, 2016.

[20] C. Siau, A. Karim, M. Norziah, and W. Wan Rosli, "Effects of cationization on DSC thermal profiles, pasting and emulsifying properties of sago starch," Journal of the Science of Food and Agriculture, vol. 84, no. 13, pp. 1722-1730, 2004.

[21] F. Xie, L. Yu, H. Liu, and L. Chen, "Starch modification using reactive extrusion," Journal on Starch, vol. 58, pp. 131-139, 2016.

[22] Z. Huang, J. Lu, X. Li, and Z. Tong, "Effect of mechanical activation on physico-chemical properties and structure of cassava starch," Carbohydrate Polymers, vol. 68, no. 1, pp. 128-135, 2007.

[23] S. Emami, A. Perera, V. Meda, and R. T. Tyler, "Effect of microwave treatment on starch digestibility and physicochemical properties of three barley types," Food and Bioprocess Technology, vol. 5, no. 6, pp. 2266-2274, 2012.

[24] G. Lewandowicz, T. Jankowski, and J. Fornal, "Effect of microwave radiation on physico-chemical properties and structure of cereal starches," Carbohydrate Polymers, vol. 42, no. 2, pp. 193-199, 2000.

[25] R. Czechowska-Biskup, B. Rokita, S. Lotfy, P. Ulanski, and J. M. Rosiak, "Degradation of chitosan and starch by $360-\mathrm{kHz}$ ultrasound," Journal on Carbohydr. Polym., vol. 60, pp. 175184, 2013.

[26] Z. Luo, X. Fu, X. He, F. Luo, Q. Gao, and S. Yu, "Effect of ultrasonic treatment on the physicochemical properties of maize starches differing in amylose content," Journal on Starch, vol. 60, pp. 646-653, 2013.

[27] A. Gunaratne and R. Hoover, "Effect of heat-moisture treatment on the structure and physicochemical properties of 
tuber and root starches," Carbohydrate Polymers, vol. 49, no. 4, pp. 425-437, 2002.

[28] H.-J. Chung, H. S. Lim, and S.-T. Lim, "Effect of partial gelatinization and retrogradation on the enzymatic digestion of waxy rice starch," Journal of Cereal Science, vol. 43, no. 3, pp. 353-359, 2006.

[29] B. Kaur, F. Ariffin, R. Bhat, and A. A. Karim, "Progress in starch modification in the last decade," Food Hydrocolloids, vol. 26, no. 2, pp. 398-404, 2012.

[30] Y. N. Shariffa, A. A. Karim, A. Fazilah, and I. S. M. Zaidul, "Enzymatic hydrolysis of granular native and mildly heattreated tapioca and sweet potato starches at sub-gelatinization temperature," Food Hydrocolloids, vol. 23, no. 2, pp. 434-440, 2009.

[31] R. Liao, J. Xu, and K. Umemura, "Low density sugarcane bagasse particleboard bonded with citric acid and sucrose: effect of board density and additive," Journal for Bioresources, vol. 11, pp. 2174-2185, 2016.

[32] M. E. Selamat, O. Sulaiman, R. Hashim et al., "Measurement of some particleboard properties bonded with modified carboxymethyl starch of oil palm trunk," Measurement, vol. 53, pp. 251-259, 2014.

[33] J. Y. Shi and Y. Y. Tang, "Study on the rice straw-particleboard by starch-based API adhesive," Advanced Materials Research, vol. 113-116, pp. 1017-1020, 2010.

[34] I. Spiridon, C.-A. Teaca, and R. Bodirlau, "Preparation and characterization of adipic acid-modified starch microparticles/plasticized starch composite films reinforced by lignin," Journal of Materials Science, vol. 46, no. 10, pp. 3241-3251, 2010.

[35] B. Ndazi, J. V. Tesha, and E. T. N. Bisanda, "Some opportunities and challenges of producing bio-composites from non-wood residues," Journal of Materials Science, vol. 41, no. 21, pp. 6984-6990, 2006.

[36] J. W. Lawton, "Starch, uses of native starch," in Reference Module in Food Science, Elsevier, Amsterdam, Netherlands, 2016.

[37] Y. Kulshreshtha, E. Schlangen, H. M. Jonkers, P. J. Vardon, and L. A. van Paassen, "Corncrete: a corn starch based building material," Construction and Building Materials, vol. 154, pp. 411-423, 2017.

[38] D. W. S. Wong, "Carbohydrates," in Mechanism and Theory in Food Chemistry, pp. 123-168, Springer, Berlin, Germany, 2nd edition, 2017.

[39] C. S. Miranda, M. S. Ferreira, M. T. Magalhães et al., "Mechanical, thermal and barrier properties of starch-based films plasticized with glycerol and lignin and reinforced with cellulose nanocrystals," Materials Today: Proceedings, vol. 2, no. 1, pp. 63-69, 2015.

[40] S. F. Alessandra, R. Joabel, B. Lina et al., "Biocomposite of cassava starch reinforced with cellulose pulp fibers modified with deposition of silica $\left(\mathrm{SiO}_{2}\right)$ nanoparticles," Journal of Nanomaterials, vol. 2015, Article ID 493439, 9 pages, 2015.

[41] J. C. Oliveira, C. S. Miranda, M. S. Ferreira et al., "Starchbased films plasticized with glycerol and lignin from piassava fiber reinforced with nanocrystals from Eucalyptus," Materials Today: Proceedings, vol. 2, no. 1, pp. 134-140, 2015.

[42] S. Othman, K. M. Salleh, H. Rokiah et al., "Evaluation of properties of starch-based adhesives and particleboard manufactured from them," Journal of Adhesion Science and Technology, vol. 29, pp. 319-336, 2015.

[43] H. B. Nurul, M. Mazlan, M. A. Mohd et al., "Potential of cassava root as a raw material for bio-composite development," Journal of Engineering and Applied Sciences, vol. 11, no. 9, 2016.

[44] D. F. Coral, G. P. Pineda, R. A. Rosales, and G. M. E. Rodriguez, "Determination of the gelatinization temperature of starch presented in maize flours," in Proceedings of the XIX Latin American Symposium on Solid State Physics (SLAFES XIX), Puerto Iguazú, Argentina, October 2018.

[45] S. H. Imam, C. Bilbao-Sainz, B.-S. Chiou, G. M. Glenn, and W. J. Orts, "Biobased adhesives, gums, emulsions, and binders: current trends and future prospects," Journal of Adhesion Science and Technology, vol. 27, no. 18-19, pp. 1972-1997, 2013.

[46] A. K. Mohanty, M. Misra, and L. T. Drzal, "Sustainable biocomposites from renewable resources:opportunities and challenges in the green materials world," Journal of Polymers and the Environment, vol. 10, no. 1-2, pp. 19-26, 2002.

[47] S. Laurichesse and L. Avérous, "Chemical modification of lignins: towards biobased polymers," Progress in Polymer Science, vol. 39, no. 7, pp. 1266-1290, 2014.

[48] E.-D. Wong, M. Zhang, Q. Wang, and S. Kawai, "formation of the density profile and its effects on the properties of particleboard," Wood Science and Technology, vol. 33, no. 4, pp. 327-340, 1999.

[49] Z. Majeed, N. Mansor, S. Ismail, R. Mathialagan, and Z. Man, "Gompertz kinetics of soil microbial biomass in response to lignin reinforcing of urea-crosslinked starch films," Procedia Engineering, vol. 148, pp. 553-560, 2016.

[50] I. Khan, M. Mansha, and M. A. J. Mazumder, "Polymer blends," in Polymers and Polymeric Composites: A Reference Series, pp. 1-38, Springer, Cham, Switzerland, 2018.

[51] C. W. Dence, "The determination of lignin," in Methods in Lignin Chemistry, pp. 33-61, Springer-Verlag, Berlin, Germany, 1992.

[52] C. J. Vengal and M. Srikumar, "Processing and study of novel lignin-starch and lignin-gelatin biodegradable polymeric films," Trends in Biomaterials and Artificial Organs, vol. 18, no. 2, 2005.

[53] J. Holm, I. Björck, A. Drews, and N.-G. Asp, "A rapid method for the analysis of starch," Starch-Stärke, vol. 38, no. 7, pp. 224-226, 1986.

[54] N. S. Sulaiman, R. Hashim, M. H. Mohamad Amini, O. Sulaiman, and S. Hiziroglu, "Evaluation of the properties of particleboard made using oil palm starch modified with epichlorohydrin," Journal for BioResources, vol. 8, no. 1, pp. 283-301, 2012

[55] Z. Anwar, M. Gulfraz, and M. Irshad, "Agro-industrial lignocellulosic biomass a key to unlock the future bio-energy: a brief review," Journal of Radiation Research and Applied Sciences, vol. 7, no. 2, pp. 163-173, 2014.

[56] A. A. Zarifa, M. A. Shammala, and A. A. Sheikh, "Sustainable manufacturing of particleboards from sawdust and agricultural waste mixed with recycled plastics," Journal for Environmental Engineering, vol. 8, pp. 174-180, 2018.

[57] G. Nemli, S. Demirel, E. Gümüşkaya, M. Aslan, and C. Acar, "Feasibility of incorporating waste grass clippings (Lolium perenne L.) in particleboard composites," Waste Management, vol. 29, no. 3, pp. 1129-1131, 2009.

[58] M. Akgul, C. Guler, and Y. Copur, "Certain physical and mechanical properties of medium density fiberboards manufactured from blends of corn (Zea mays indurata sturt.) stalks and pine (pinus nigra) wood," Turkish Journal of Agriculture, vol. 34, pp. 197-206, 2010. 
[59] W. Razak, A. S. Mohammed, S. Othman, S. Mahmud, W. S. Hashim, and S. R. Mohd, "Properties of engineered oil palm composite boards from 32 Year-old tree stems," Journal on Agricultural and Biological Science, vol. 8, 2013.

[60] P. Rachtanapun, P. Simasatitkul, W. Chaiwan, and Y. Watthanaworasakun, "Effect of sodium hydroxide concentration on properties of carboxymethyl rice starch," Journal for Food Research, vol. 19, pp. 923-931, 2012.

[61] S. Sam-Brew and G. D. Smith, "Flax shive and hemp hurd residues as alternative raw material for particleboard production," Journal for BioResource, vol. 12, pp. 5715-5735, 2017.

[62] H. C. Srivastava, R. S. Parmar, and G. B. Dave, "Studies on Dextrinization. Part I. Pyrodextrinization of Corn Starch in the Absence of Any Added Catalyst," Starch-Stärke, vol. 22, no. 2, pp. 49-54, 1970.

[63] L. Rautkari, C. A. S. Hill, S. Curling, Z. Jalaludin, and G. Ormondroyd, "What is the role of the accessibility of wood hydroxyl groups in controlling moisture content?," Journal of Materials Science, vol. 48, no. 18, pp. 6352-6356, 2013.

[64] Y. Zuo, W. Liu, J. Xiao, X. Zhao, Y. Zhu, and Y. Wu, "Preparation and characterization of dialdehyde starch by one-step acid hydrolysis and oxidation," International Journal of Biological Macromolecules, vol. 103, pp. 1257-1264, 2017.

[65] A. Olumoyewa, C. Osueke, S. Badiru et al., "Evaluation of particle board from sugarcane bagasse and corn cob," Journal for Mechanical Engineering and Technology, vol. 10, pp. 1193-1200, 2019.

[66] J. Khazaei, "Water absorption characteristics of three wood varieties," Cercetari Agronomice in Moldova, vol. 41, pp. 134-145, 2008.

[67] M. V. Scatolino, D. W. Silva, R. F. Mendes, and L. M. Mendes, "Use of maize cob for production of particleboard," Ciência e Agrotecnologia, vol. 37, no. 4, pp. 330-337, 2013.

[68] H. Abdolzadeh, K. Doosthoseini, A. N. Karimi, and A. A. Enayati, "The effect of acetylated particle distribution and type of resin on physical and mechanical properties of poplar particleboard," European Journal of Wood and Wood Products, vol. 69, no. 1, pp. 3-10, 2010.

[69] E. M. Ciannamea, P. M. Stefani, and R. A. Ruseckaite, "Medium-density particleboards from modified rice husks and soybean protein concentrate-based adhesives," Bioresource Technology, vol. 101, no. 2, pp. 818-825, 2010.

[70] M. Y. Dizaj, A. Khazaeiana, and A. Ashorib, "Suitability of sorghum stalk fibers for production of particleboard," Journal for Carbohydrate Polymers, vol. 120, pp. 15-21, 2015.

[71] Y. Zuo, X. Zhang, and X. Liu, "Study on the effect of organic additives and inorganic fillers on properties of sodium silicate wood adhesive modified by polyvinyl alcohol," Journal for BioResource, vol. 10, pp. 1528-1542, 2015.

[72] R. E. M. Garcia and N. M. Gonzalez, "Effect of the addition of potassium and magnesium ions on the thermal, pasting, and functional properties of plantain starch (musa paradisiaca)," Journal of Biological Macromolecules, vol. 124, pp. 41-49, 2019.

[73] R. Garcia, A. R. Lopez, and M. A. Villegas, "The effect of $\mathrm{Ca}^{2+}$ ions on the pasting, morphological, structural, vibrational, and mechanical properties of corn starch-water system," Journal of Cereal Science, vol. 79, pp. 174-182, 2017.

[74] A. Koubaa and Z. Koran, "Measure of the internal bond strength of paper/board," Tappi Journal, vol. 78, pp. 103-111, 1995.

[75] X. Peng, L. Zhong, J. Ren, and R. Sun, "Laccase and alkali treatments of cellulose fibre: surface lignin and its influences on fibre surface properties and interfacial behaviour of sisal fibre/phenolic resin composites," Composites Part A: Applied Science and Manufacturing, vol. 41, no. 12, pp. 1848-1856, 2010.

[76] M. S. Sreekala, "Oil palm fibre reinforced phenol Formaldehyde composites: influence of fibre surface modifications on the mechanical performance," Applied Composite Materials, vol. 7, no. 5/6, pp. 295-329, 2000.

[77] A. Taramian, K. Doosthoseini, S. A. Mirshokraii, and M. Faezipour, "Particleboard manufacturing: an innovative way to recycle paper sludge," Waste Management, vol. 27, no. 12, pp. 1739-1746, 2007.

[78] V. Laemlaksakul, "Physical and mechanical properties of particleboard from bamboo waste," Journal for Engineering and Technology, vol. 4, pp. 276-280, 2010.

[79] H. Rokiah, S. Norhafizah, S. Othman et al., "Effect of particle geometry on the properties of binderless particleboard manufactured from oil palm trunk," Journal on Materials and Design, vol. 31, no. 9, pp. 4251-4257, 2010.

[80] N. Reddy and Y. Yang, "Citric acid cross-linking of starch films," Food Chemistry, vol. 118, no. 3, pp. 702-711, 2010.

[81] Y. Guangbao, Synthesis and Characterization of Cellulose Fiber-Silica Nanocomposites, Department of Chemical Engineering, Lappeenranta University of Technology, Faculty of Technology, Lappeenranta, Finland, 2014. 


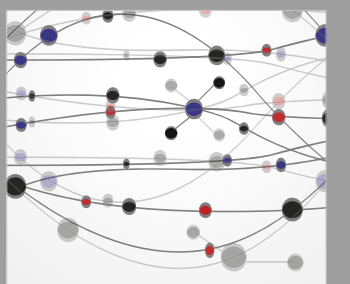

The Scientific World Journal
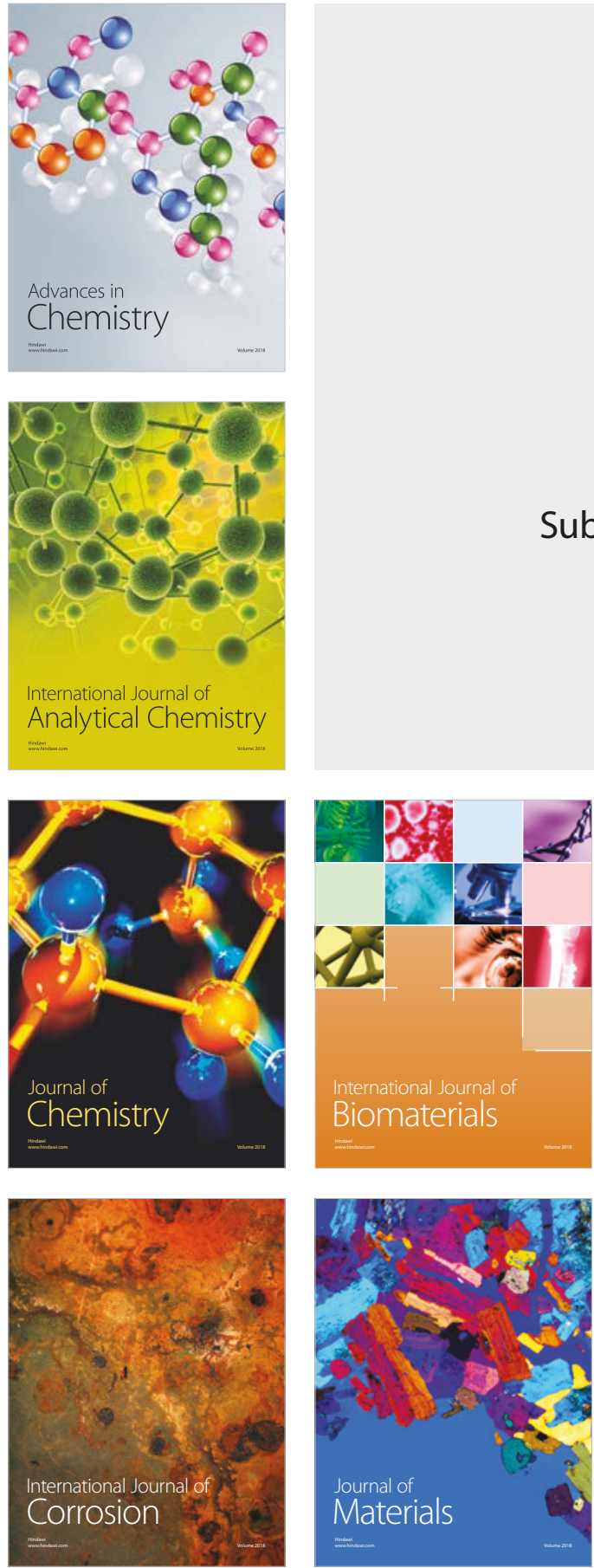

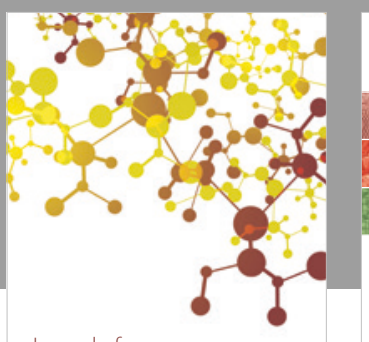

Journal of

Applied Chemistry
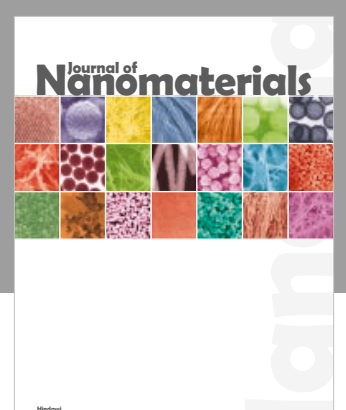

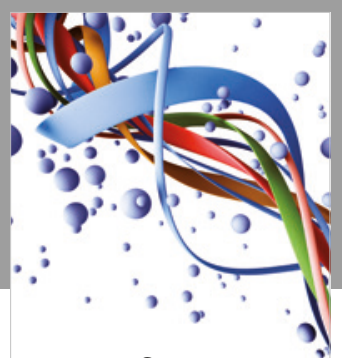

Scientifica

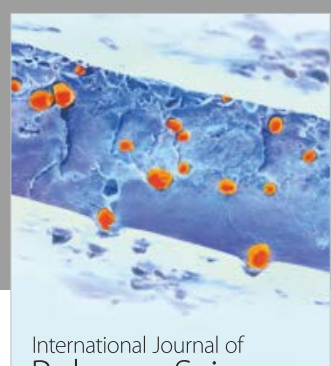

Polymer Science

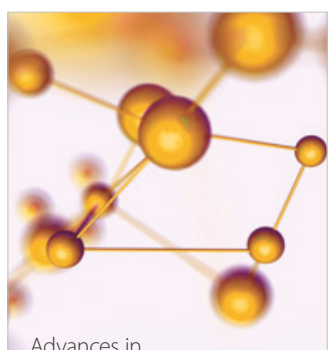

Physical Chemistry
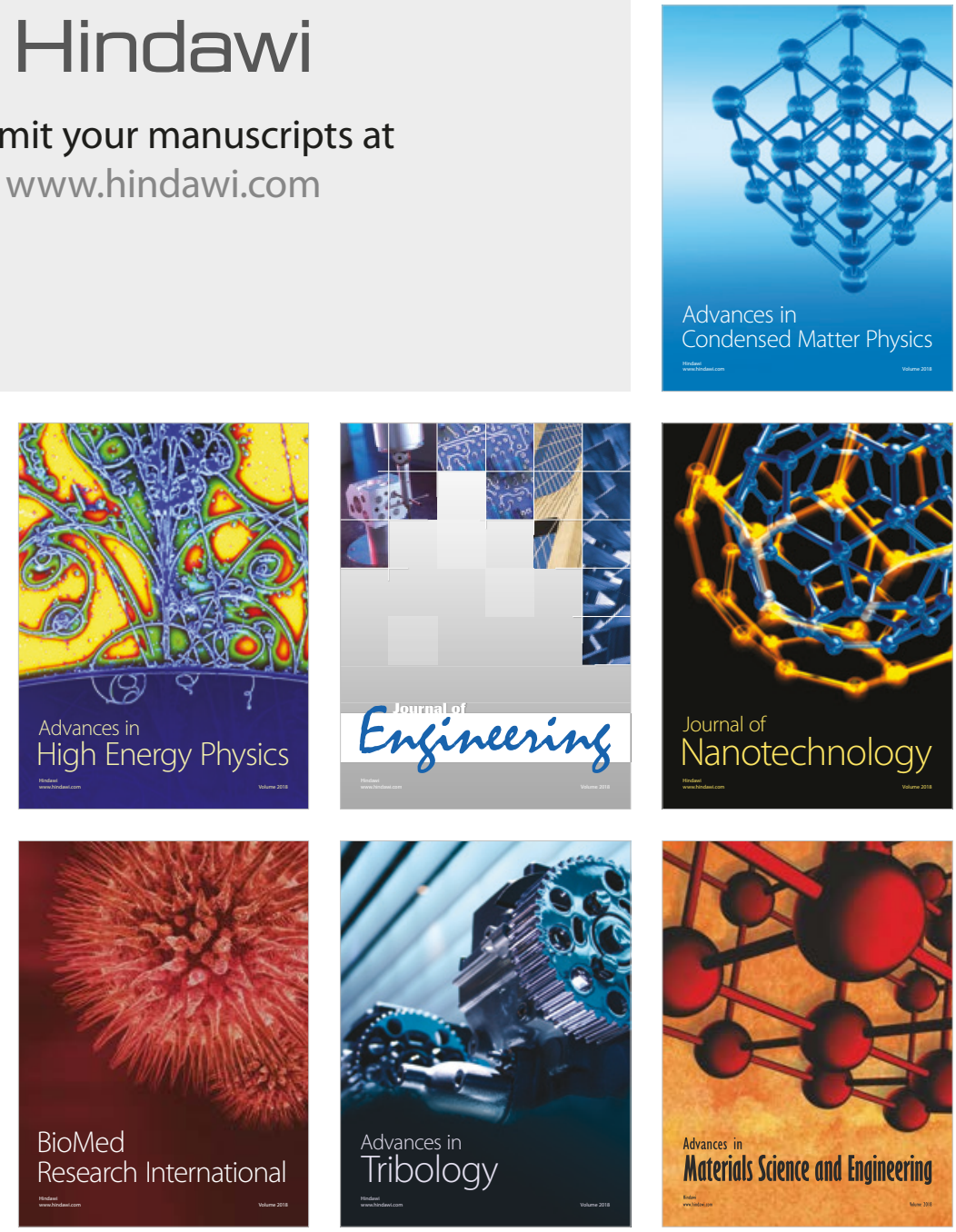